Article

\title{
Oxyresveratrol: Structural Modification and Evaluation of Biological Activities
}

\author{
Nutputsorn Chatsumpun ${ }^{1}$, Taksina Chuanasa ${ }^{1}$, Boonchoo Sritularak ${ }^{1}$, Vimolmas Lipipun ${ }^{2}$, \\ Vichien Jongbunprasert ${ }^{1}$, Somsak Ruchirawat ${ }^{3}$, Poonsakdi Ploypradith ${ }^{3, *}$ and \\ Kittisak Likhitwitayawuid ${ }^{1, *}$ \\ 1 Department of Pharmacognosy and Pharmaceutical Botany, Faculty of Pharmaceutical Sciences, \\ Chulalongkorn University, Bangkok 10330, Thailand; manee_many@hotmail.com (N.C.); \\ s_taksina@yahoo.com (T.C.); Boonchoo.Sr@chula.ac.th (B.S.); Vichien.J@chula.ac.th (V.J.) \\ 2 Department of Biochemistry and Microbiology, Faculty of Pharmaceutical Sciences, \\ Chulalongkorn University, Bangkok 10330, Thailand; Vimolmas.L@chula.ac.th \\ 3 Laboratory of Medicinal Chemistry, Chulabhorn Research Institute, and Program in Chemical Biology, \\ Chulabhorn Graduate Institute, 54 Kampaeng Phet 6 Road, Bangkok 10210, Thailand; somsak@cri.or.th \\ * Correspondence: poonsakdi@cri.or.th (P.P.); Kittisak.L@chula.ac.th (K.L.); \\ Tel.: +66-2-553-8555 (P.P.); +66-2-218-8360 (K.L.)
}

Academic Editors: Dominique Vervandier-Fasseur, Norbert Latruffe and Ole Vang Received: 29 February 2016; Accepted: 11 April 2016; Published: 19 April 2016

\begin{abstract}
Oxyresveratrol (2,4,3',5'-tetrahydroxystilbene, 1), a phytoalexin present in large amounts in the heartwood of Artocarpus lacucha Buch.-Ham., has been reported to possess a wide variety of biological activities. As part of our continuing studies on the structural modification of oxyresveratrol, a library of twenty-six compounds was prepared via $O$-alkylation, aromatic halogenation, and electrophilic aromatic substitution. The two aromatic rings of the stilbene system of $\mathbf{1}$ can be chemically modulated by exploiting different protecting groups. Such a strategy allows for selective and exclusive modifications on either ring A or ring B. All compounds were evaluated in vitro for a panel of biological activities, including free radical scavenging activity, DNA protective properties, antiherpetic activity, inhibition of $\alpha$-glucosidase and neuraminidase, and cytotoxicity against some cancer cell lines. Several derivatives were comparably active or even more potent than the parent oxyresveratrol and/or the appropriate positive controls. The partially etherified analogs $5^{\prime}$-hydroxy-2,3',4-trimethoxystilbene and 3',5'-dihydroxy-2,4-dimethoxystilbene demonstrated promising anti-herpetic and DNA protective activities, offering new leads for neuropreventive agent research, whereas $5^{\prime}$-hydroxy-2,3',4,-triisopropoxystilbene displayed anti- $\alpha$-glucosidase effects, providing a new lead molecule for anti-diabetic drug development. 3',5'-Diacetoxy-2,4-diisopropoxystilbene showed potent and selective cytotoxicity against HeLa cancer cells, but the compound still needs further in vivo investigation to verify its anticancer potential.
\end{abstract}

Keywords: oxyresveratrol; stilbene; free radicals; $\alpha$-glucosidase; herpes simplex; cytotoxicity; Artocarpus lacucha; Artocarpus lakoocha

\section{Introduction}

Stilbenes are a group of plant polyphenolic compounds derived from the mixed shikimate-acetate pathway. They are produced as phytoalexins, with limited but heterogeneous distribution in the plant kingdom [1]. Over the years, these C6-C2-C6 compounds, as well as their oligomers, have attracted significant research attention due to their elaborate and diverse structures, and wide-ranging biological activities [2]. Historically, these compounds have been studied for antioxidant, antibacterial, antiviral and anticancer activities [3,4]. However, recent efforts have been made to explore other potential uses 
such as therapeutic or preventive agents against non-communicable diseases (NCDs), for example, diabetes mellitus (DM), cardiovascular illnesses, and Parkinson's disease (PD) [5-7].

Oxyresveratrol $\left(2,4,3^{\prime}, 5^{\prime}\right.$-tetrahydroxystilbene, 1, Scheme 1) is present in large amounts in the heartwood of Artocarpus lacucha Buch.-Ham. (also known as Artocarpus lakoocha Roxb.) [8], and thus offers opportunities for chemical and biological studies. Our previous in vitro and in vivo experiments have shown that $\mathbf{1}$ is a potent tyrosinase inhibitor, and subsequent studies in human volunteers have confirmed it as an effective skin-whitening agent $[9,10]$. Despite its moderate in vitro inhibitory activity against herpes simplex virus type I (HSV-1) [11], compound 1, in the form of topical cream, exhibited high therapeutic efficacy in mice cutaneously infected with HSV-1, with a potency comparable to that of the antiviral drug acyclovir [12]. Currently, mounting evidence has indicated HSV-1 infection in the brain as one of the key causative factors in the pathogenesis of Alzheimer's disease (AD) [13], and this has suggested another medicinal importance for oxyresveratrol. Regarding the AD preventive potential, 1 has been reported to inhibit $\beta$-amyloid-induced neurotoxicity in cultured cortical neurons and in vitro activity of $\beta$-secretase, an enzyme vital for the production of the A $\beta$ protein $[14,15]$. In addition, the compound has been studied for protective activity against Parkinson's disease (PD) in cultured neuronal cells [16], and demonstrated to prevent neurotoxicity and DNA damage through its antioxidant properties $[17,18]$. Compound 1 showed modest inhibitory activity against H5N1 neuraminidase (an enzyme found in avian influenza virus) [19], but strong inhibition against $\alpha$-glucosidase, an enzyme responsible for the breaking down of starch and polysaccharides into glucose in the intestine [20]. In spite of all the potential uses mentioned above, $\mathbf{1}$ seems to have rather limited clinical application. The compound has been reported to undergo extensive hepatic metabolism and rapid urinary elimination, resulting in a short half-life time, and thereby restricting its clinical use [21]. Moreover, its postulated function as a preventive agent for neurodegenerative disorders, such as AD or PD, appears to be hindered by its low ability to cross the blood-brain barrier (BBB) [22].

In our earlier report, we described a successful structural modification of $\mathbf{1}$, which gave an analog with enhanced tyrosinase inhibitory activity [9]. In this investigation, we broadened our chemical studies and expanded the biological evaluations with the intention of improving the following biological activities of 1: antioxidant and DNA protective properties, inhibitory activities against the enzymes $\alpha$-glucosidase and neuraminidase, and ability to inhibit the growth of herpes simplex virus and some cancer cells.

\section{Results and Discussion}

\subsection{Chemistry}

\subsubsection{O-Alkylation/O-Acylation}

When 1 was allowed to react with $\mathrm{MeI}$ in acetone at room temperature, di-, tri- and tetra-O-methylated products $(2,3$ and 4 ) were obtained in $9 \%, 25 \%$, and $45 \%$ yields, respectively (Scheme 1). The alkylation of 1 with 2-bromopropane $/ \mathrm{K}_{2} \mathrm{CO}_{3}$ in DMF gave the corresponding di-, triand tetra-O-isopropyl compounds (5, 6 and 7) in 24\%, 30\%, and 28\% yields, respectively (Scheme 1). It should be noted that it was difficult to avoid the formation of 7, perhaps due to the greater solubility of the more alkylated ethers in DMF under the reaction conditions. In both $\mathrm{O}$-alkylation reactions, the di-O-alkylation occurred on the two hydroxy groups of ring A, and tri-O-alkylation occupied both hydroxy groups of ring $\mathrm{A}$ and a hydroxy group of ring $\mathrm{B}$. These results suggested that the phenolic groups on ring $A$ were more reactive than their counterparts on ring $B$, most likely due to the conjugation of the hydroxy groups of ring A with the olefinic bond, which is not possible for those on ring B. This difference in the reactivity of the hydroxy groups was exploited in the subsequent studies on the aromatic electrophilic substitution reactions, in which the isopropyl group was found to be a better $O$-protecting group than the methyl after some experimentation (see below). Acetylation of 1 with $\mathrm{AcCl}$ gave 8 in $70 \%$ yield. 
O-Alkylation of the tri-O-isopropyl compound 6 with ethyl bromoacetate under basic conditions went smoothly, to furnish in $84 \%$ yield the ethyl ester 9, which then underwent $\mathrm{BCl}_{3}$-mediated deprotection of the isopropyl groups to give the trihydroxy compound $\mathbf{1 0}$ in $61 \%$ yield. Subsequent saponification of the ethyl ester using $5 \% \mathrm{KOH}$ in ethanol provided the corresponding acid $\mathbf{1 1}$ in a moderate $40 \%$ yield (Scheme 1 ).

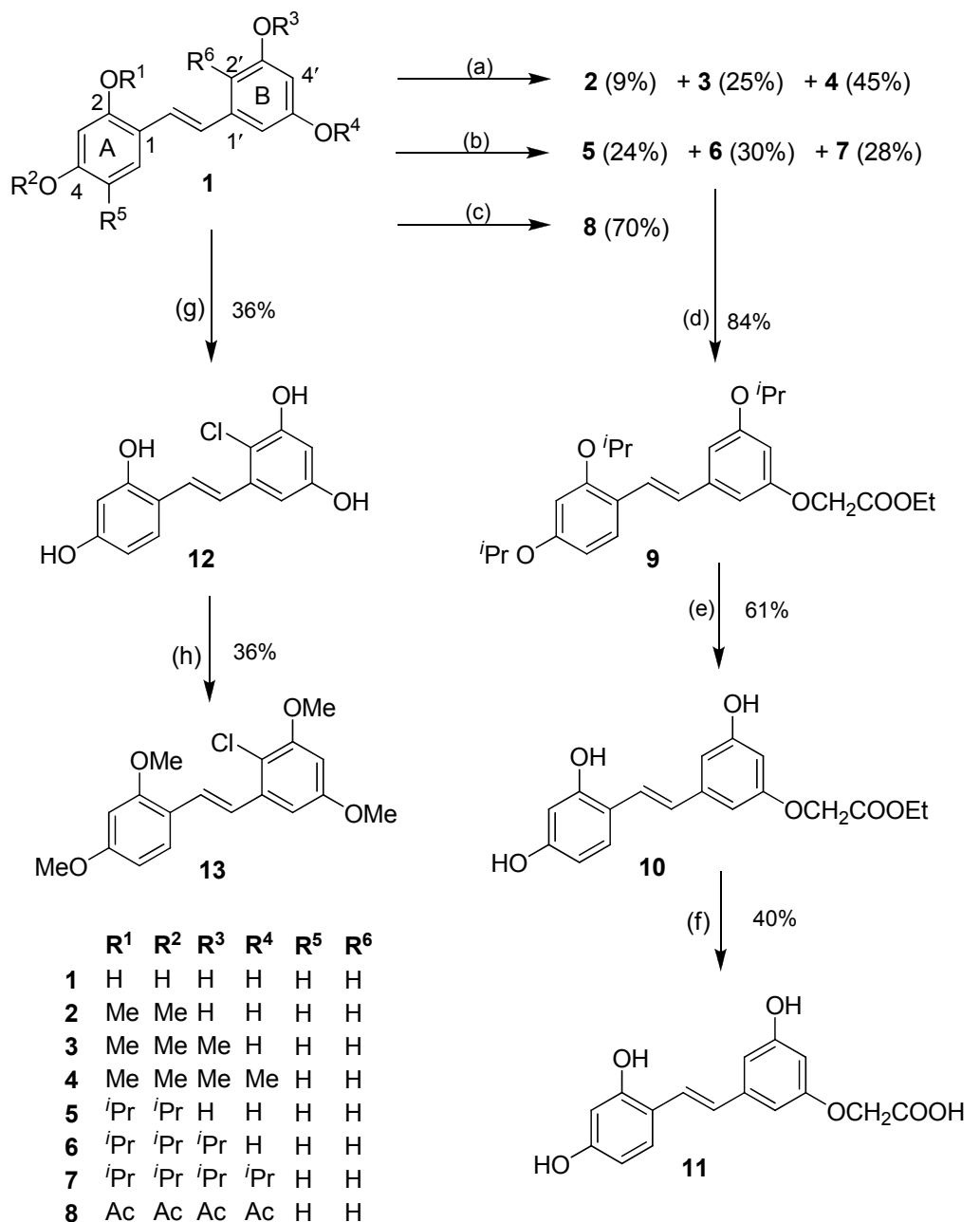

Scheme 1. O-Alkylation, acylation, and aromatic chlorination of 1. Reagents and conditions: (a) MeI, $\mathrm{K}_{2} \mathrm{CO}_{3}$, acetone, $\mathrm{rt}$; (b) 2-bromopropane, $\mathrm{K}_{2} \mathrm{CO}_{3}, \mathrm{DMF}, 55^{\circ} \mathrm{C}$; (c) $\mathrm{AcCl}, \mathrm{Et}_{3} \mathrm{~N}, \mathrm{DMAP}_{2} \mathrm{CH}_{2} \mathrm{Cl}_{2}, \mathrm{rt}$; (d) ethyl bromoacetate, $\mathrm{K}_{2} \mathrm{CO}_{3}, \mathrm{DMF}, \mathrm{rt}$; (e) $\mathrm{BCl}_{3}, \mathrm{CH}_{2} \mathrm{Cl}_{2},-78{ }^{\circ} \mathrm{C} \rightarrow \mathrm{rt}$, $\mathrm{Ar}$; (f) $5 \% \mathrm{KOH}, \mathrm{EtOH}, \mathrm{rt}$; (g) $\mathrm{NCS}, \mathrm{AcOH}$ (glacial), rt; (h) $\mathrm{MeI}, \mathrm{K}_{2} \mathrm{CO}_{3}$, acetone, $55^{\circ} \mathrm{C}$.

\subsubsection{Halogenation}

It was expected that aromatic halogenation on 1 would be facile due to the high electron density contributed by the hydroxy groups. Due to the conjugation between the hydroxy groups on ring A and the olefin, the aromatic B ring should be more nucleophilic, particularly at the positions $2^{\prime} / 6^{\prime}$, and this difference should facilitate regioselective electrophilic aromatic halogenation under appropriate and mild conditions. Using N-chlorosuccinimide (NCS) and glacial acetic acid, the corresponding $2^{\prime}$-monochlorinated product 12 was obtained from 1 in 36\% yield (Scheme 1). Chlorination on 7 and 20 (prepared from 5) did not give the desired chlorinated product. Compound 12 smoothly underwent full methylation to give the tetramethylether 13 in 36\% yield. Several attempts to carry out aromatic bromination on $\mathbf{1}$ or 4 with $N$-bromosuccinimide under various conditions were performed, but failed to give the brominated product. Iodination of $\mathbf{1}$ with $N$-iodosuccinimide was also not successful. 


\subsubsection{Aromatic Electrophilic Substitution}

When the tetra-O-isopropyl compound 7 reacted under the Vilsmeier-Haack formylation conditions, the corresponding ring $B$-formylated product $\mathbf{1 4}$ was obtained in good yield $(80 \%)$ (Scheme 2).

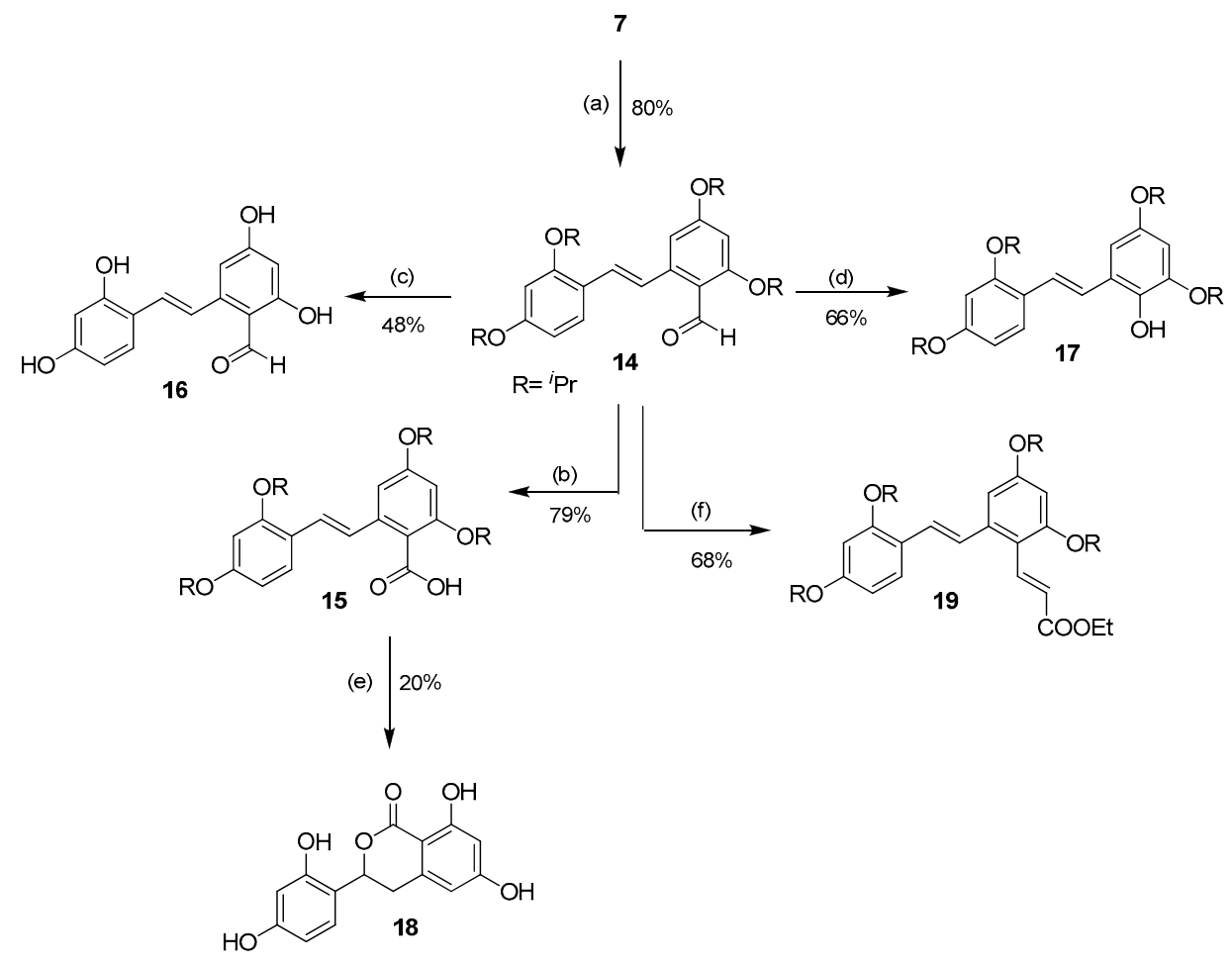

Scheme 2. Selective aromatic formylation of ring B of $\mathbf{7}$ to $\mathbf{1 4}$ and the subsequent derivatizations of the aldehyde. Reagents and conditions: (a) $\mathrm{POCl}_{3}, \mathrm{DMF}, 0{ }^{\circ} \mathrm{C}, \mathrm{Ar}$; (b) $\mathrm{NaClO}_{2}, \mathrm{NaH}_{2} \mathrm{PO}_{4} \cdot 2 \mathrm{H}_{2} \mathrm{O}$, 2-methyl-2-butene, acetone, $\mathrm{rt}$; (c) $\mathrm{BCl}_{3}, \mathrm{CH}_{2} \mathrm{Cl}_{2},-78{ }^{\circ} \mathrm{C} \rightarrow \mathrm{rt}$, $\mathrm{Ar}$; (d) $p$ - $\mathrm{TsOH} \cdot \mathrm{H}_{2} \mathrm{O}, \mathrm{H}_{2} \mathrm{O}_{2}, 0{ }^{\circ} \mathrm{C}, \mathrm{Ar}$; (e) $\mathrm{BBr}_{3}, \mathrm{CH}_{2} \mathrm{Cl}_{2},-78{ }^{\circ} \mathrm{C} \rightarrow \mathrm{rt}$, Ar; (f) $\mathrm{EtOOCCH}=\mathrm{PPh}_{3}, \mathrm{CH}_{2} \mathrm{Cl}_{2}, 0^{\circ} \mathrm{C}$.

The aldehyde functional group could be further oxidized to the corresponding carboxylic acid $\mathbf{1 5}$ in $79 \%$ yield using sodium chlorite. The aldehyde 14 smoothly underwent $\mathrm{BCl}_{3}$-mediated deprotection of the isopropyl groups to provide the 2 -formyloxyresveratrol 16 in moderate $48 \%$ yield. In addition, the aldehyde 14 could also undergo the acid-mediated Baeyer-Villiger-type Dakin reaction, which converted the aldehyde into the corresponding formate. Subsequent in situ cleavage of the formate under the reaction conditions furnished $2^{\prime}$-hydroxy-tetra-O-isopropyl oxyresveratrol $\mathbf{1 7}$ in good yield (66\%). Unfortunately, all attempts to deprotect the isopropyl groups of $\mathbf{1 7}$ failed, and only a mixture of decomposed products was obtained. The deisopropylation of $\mathbf{1 5}$ with $\mathrm{BBr}_{3}$ under similar conditions unexpectedly gave the isochromanone 18 in $20 \%$ yield, a result of the Lewis acid-mediated removal of the $\mathrm{O}$-isopropyl groups followed by $\mathrm{C}-\mathrm{O}$ bond formation on the olefinic carbon of the stilbene system. In addition, the aldehyde $\mathbf{1 4}$ could undergo a smooth Wittig olefination to furnish the stilbenyl cinnamate 19 in $68 \%$ yield.

In order to effect the reactions on ring A of oxyresveratrol, the di-O-isopropyl compound 5 was acetylated under standard conditiond to provide ring A-di-O-isopropyl ring B-di-O-acetyl compound 20 in 74\% yield (Scheme 3). 


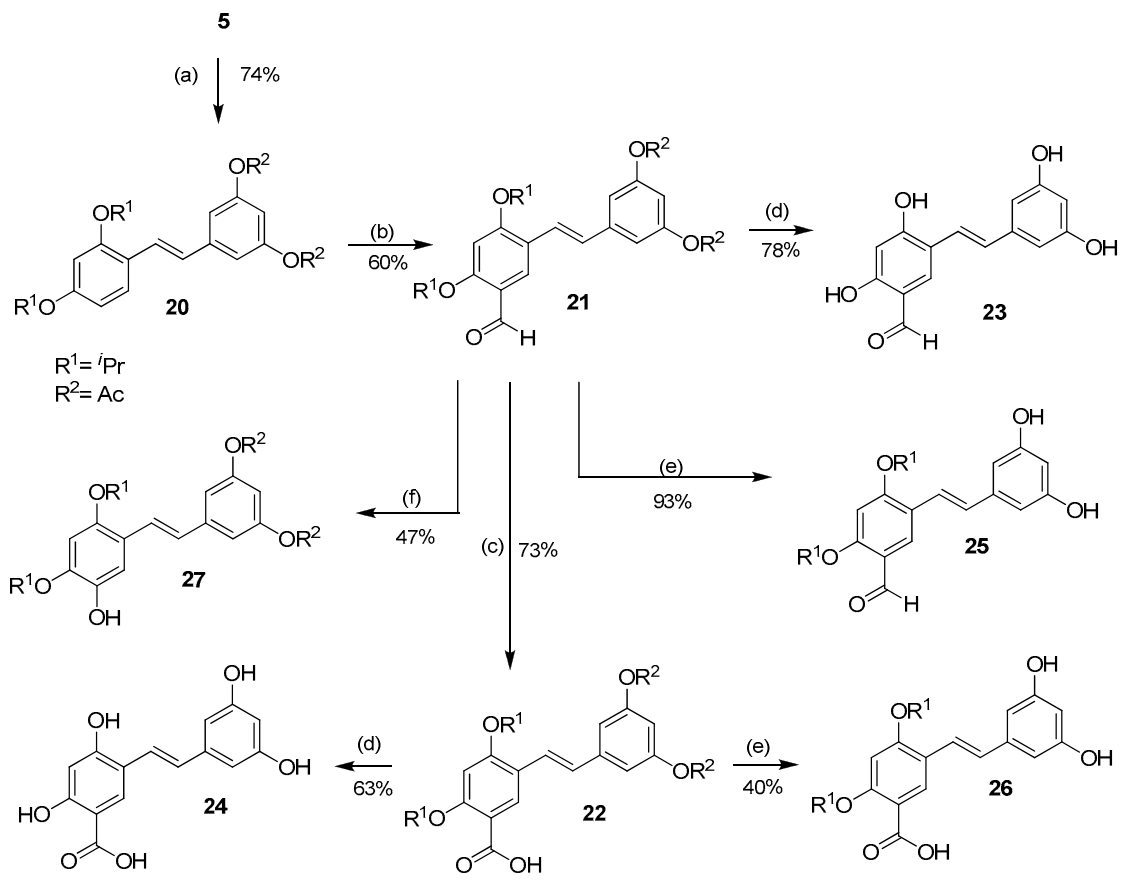

Scheme 3. Protecting group-directed selective aromatic formylation of ring A of 20 to 21 and the subsequent derivatizations of the aldehyde. Reagents and conditions: (a) $\mathrm{Ac}_{2} \mathrm{O}, \mathrm{Et}_{3} \mathrm{~N}, \mathrm{CH}_{2} \mathrm{Cl}_{2}, \mathrm{rt}$; (b) $\mathrm{POCl}_{3}, \mathrm{DMF}, 0^{\circ} \mathrm{C}, \mathrm{Ar} ;$ (c) $\mathrm{NaClO}_{2}, \mathrm{NaH}_{2} \mathrm{PO}_{4} \cdot 2 \mathrm{H}_{2} \mathrm{O}$, 2-methyl-2-butene, acetone, rt; (d) $\mathrm{BCl}_{3}, \mathrm{CH}_{2} \mathrm{Cl}_{2}$, $-78{ }^{\circ} \mathrm{C} \rightarrow \mathrm{rt}, \mathrm{Ar}$; (e) $5 \% \mathrm{KOH}, \mathrm{EtOH}, \mathrm{rt}$; (f) $p$ - TsOH$\cdot \mathrm{H}_{2} \mathrm{O}, \mathrm{H}_{2} \mathrm{O}_{2}, 0{ }^{\circ} \mathrm{C}$.

After some experimentation, ring A was formylated on the 5-position to give 21 exclusively, in $60 \%$ yield, under the best Vilsmeier-Haack conditions $\left(10\right.$ eq of $\mathrm{POCl}_{3}$ at $0{ }^{\circ} \mathrm{C} \rightarrow \mathrm{rt}$ overnight under argon). Subsequent oxidation of the aldehyde 21 to the corresponding acid 22 using sodium chlorite gave the latter in $73 \%$ yield. $\mathrm{BCl}_{3}$-mediated cleavage of all the $O$-isopropyl groups as well as the $\mathrm{O}$-acetyl groups of $\mathbf{2 1}$ and $\mathbf{2 2}$ finally gave the desired 5-formyl- and 5-carboxyoxyresveratrols 23 and 24 in $78 \%$ and $63 \%$ yields, respectively. Saponification of 21 and 22 using $5 \% \mathrm{KOH}$ in ethanol to cleave the acetate groups gave 5-formyl- and 5-carboxy-di-O-isopropyl oxyresveratrol 25 and 26 in $93 \%$ and $40 \%$ yields, respectively. The aldehyde 21 was subjected to the Dakin reaction to give 5-hydroxy-di-O-acetyl-di-O-isopropyl oxyresveratrol 27 in $47 \%$ yield.

It is worth noting that the differences between protecting groups could be used to manipulate the selectivity of the aromatic electrophilic reactions. In the Vilsmeier-Haack reaction of the tetra-O-isopropyl compound 7 , all the protecting groups were electron-donating groups, which made the $2^{\prime}$ and $6^{\prime}$ positions of ring $B$ the most reactive ones, but in the Vilsmeier-Haack reaction of the di-O-acetyl-di-O-isopropyl compound 20, the acetyl groups were electron-withdrawing groups, and thus reduced the electron density of ring $\mathrm{B}$. This was virtually equivalent to the deactivation of ring $\mathrm{B}$, and therefore directed the formylation to occur on ring A. This synthetic strategy could be a useful tool for the synthesis of other similar analogs derivable from exploiting the difference in electron density of each aromatic ring.

\subsection{Biological Activity}

Since 1 was previously studied and reported to exhibit an array of biological activities including antioxidant activity and inhibition of the $\alpha$-glucosidase and neuraminidase enzymes and HSV- 1 (vide supra), all structurally modified analogs of $\mathbf{1}$ were subjected to the related assays to study the effects of such modification on each biological activity. In addition, these compounds were also evaluated for cytotoxic potential against four cancer cell lines of three different cancer types (breast, cervical and lung). 


\subsubsection{Free Radical Scavenging Activity}

First, examinations were conducted on the relationships between the phenolic and olefinic functionalities of the core stilbene structure and the free radical scavenging and DNA protective activities. Then, investigations were carried out to study how the nature and position of substituents with electron-withdrawing (i.e., $\mathrm{Cl}, \mathrm{CHO}$ and $\mathrm{COOH}$ ) or electron-donating (i.e., $\mathrm{OH}$ ) properties on the aromatic rings affected these biological activities. Compounds were first evaluated at $100 \mu \mathrm{g} / \mathrm{mL}$, and those that showed $>80 \%$ inhibition were further analyzed to determine their $\mathrm{IC}_{50}$ values.

Oxyresveratrol (1) showed weaker DPPH free radical scavenging activity than Trolox (Table 1). The phenolic groups were essential since the activity was reduced or lost when some or all of the phenolic groups of $\mathbf{1}$ were esterified/etherified, as observed in compounds $\mathbf{2 - 8}$ and $\mathbf{2 0}$. The only exception was compound 3 , the $2,4,3^{\prime}$-tri-O-methylated version of 1 , which showed higher activity against the superoxide anion radical than the parent compound. Interestingly, this compound also showed higher DNA protective properties.

Table 1. $\mathrm{IC}_{50}$ values $(\mu \mathrm{M})$ for free radical scavenging activities and DNA protective properties of $\mathbf{1}$ and derivatives.

\begin{tabular}{cccc}
\hline \multirow{2}{*}{ Compound } & \multicolumn{2}{c}{ Free Radical Scavenging Activity } & DNA Protective \\
\cline { 2 - 3 } & DPPH & Superoxide & Activity \\
\hline $\mathbf{1}$ & $11.7 \pm 0.4$ & $303.1 \pm 7.9$ & $43.3 \pm 6.7$ \\
$\mathbf{2}$ & $77.0 \pm 6.4^{*}$ & nd $\#$ & $39.4 \pm 1.2$ \\
$\mathbf{3}$ & nd & $120.1 \pm 14.9^{*}$ & $6.3 \pm 0.8^{*}$ \\
$\mathbf{5}$ & $147.7 \pm 9.8^{*}$ & nd & $59.1 \pm 9.9$ \\
$\mathbf{1 0}$ & $9.7 \pm 0.2^{*}$ & $154.9 \pm 14.7^{*}$ & $19.9 \pm 2.8^{*}$ \\
$\mathbf{1 1}$ & $19.4 \pm 3.1^{*}$ & $81.9 \pm 12.3^{*}$ & $28.6 \pm 3.8^{*}$ \\
$\mathbf{1 2}$ & $14.7 \pm 0.6^{*}$ & $98.4 \pm 7.0^{*}$ & $32.0 \pm 1.4^{*}$ \\
$\mathbf{1 6}$ & $16.5 \pm 2.8^{*}$ & $43.4 \pm 4.4^{*}$ & $32.2 \pm 4.8$ \\
$\mathbf{1 7}$ & $11.7 \pm 0.3$ & nd & nd \\
$\mathbf{1 8}$ & nd & $107.3 \pm 8.7^{*}$ & $28.3 \pm 4.3^{*}$ \\
$\mathbf{2 2}$ & nd & $17.7 \pm 3.5^{*}$ & $81.4 \pm 4.2^{*}$ \\
$\mathbf{2 3}$ & nd & $88.3 \pm 9.7^{*}$ & $54.7 \pm 8.3$ \\
$\mathbf{2 4}$ & $48.3 \pm 5.8^{*}$ & $38.6 \pm 1.4^{*}$ & $79.4 \pm 14.9^{*}$ \\
$\mathbf{2 5}$ & nd & nd & $111.8 \pm 7.3^{*}$ \\
$\mathbf{2 6}$ & nd & nd & $104.7 \pm 8.5^{*}$ \\
$\mathbf{2 7}$ & $7.0 \pm 0.2^{*}$ & nd & $18.6 \pm 3.7^{*}$ \\
Trolox & $8.7 \pm 1.1^{*}$ & $293.5 \pm 19.3$ & $113.1 \pm 4.6^{*}$ \\
\hline \#: nd $=$ not determined due to $<80^{*}$ inhibition at $100 \mu \mathrm{mg} / \mathrm{mL} . ; *$ Significantly different from that of $\mathbf{1}(p<0.05)$.
\end{tabular}

The olefinic bridge, which provided conjugation (and thus electron delocalization) between the two aromatic rings, was also required for DPPH radical scavenging ability, as demonstrated from the marked decrease in activity of $\mathbf{1 8}$. However, when evaluated against the superoxide anion, $\mathbf{1 8}$ displayed higher activity than 1 . This enhanced activity was most likely due to the electron-withdrawing effect of the $\mathrm{C}=\mathrm{O}$ of the dihydropyrone ring which helped stabilize the negatively-charged stilbene radical formed from 18 after interaction with the superoxide anion.

Introducing an electron-donating group such as $\mathrm{OH}$ to the aromatic rings could restore the lost DPPH scavenging activity caused by phenolic esterification/etherification. This was inferred by comparing the activity of the following pairs of structures: $\mathbf{7}$ (no activity) vs. 17, and $\mathbf{2 0}$ (no activity) vs. 27. However, these sets of compounds did not give similar results in the superoxide assay.

Placing an electron-withdrawing substituent, such as $\mathrm{Cl}, \mathrm{CHO}$ and $\mathrm{COOH}$, onto the aromatic ring of 1 yielded compounds 12, 16, 23 and 24 which showed weaker activity against the DPPH radical, but enhanced activity against the superoxide anion. The improved activity was likely attributable to the electron-withdrawing nature of these groups that helped to distribute the negative charge of the radicals generated from the reactions of these stilbenoids with the superoxide anion. 


\subsubsection{DNA Protective Property}

Riboflavin (RF), when exposed to light, generates several kinds of free radicals, including triplet $\left({ }^{3} \mathrm{RF} \bullet\right)$, neutral oxidized $(\mathrm{RF}(-\mathrm{H}) \bullet)$ and cation $(\mathrm{RF} \bullet+)$ riboflavin radical. The $\left({ }^{3} \mathrm{RF} \bullet\right)$ radical then transfers energy to oxygen to form reactive oxygen species (ROS) such as singlet oxygen $\left({ }^{1} \mathrm{O}_{2}\right)$ and superoxide $\left(\mathrm{O}_{2} \bullet-\right)$ radicals $[23,24]$. These free radicals, with their high energy, can each damage DNA by attacking the purine base guanine to form 8-hydroxyguanine and 2,6-diamino-4-hydroxy-5-formamidopyrimidine [23,25-27]. Any compound that can efficiently protect DNA from the damage induced by photosensitized riboflavin must be capable of scavenging or neutralizing these free radicals. In this study, compounds were first evaluated at $100 \mu \mathrm{g} / \mathrm{mL}$, and those with $>80 \%$ inhibition were further analyzed for their $\mathrm{IC}_{50}$ values (Table 1 ).

Compound 1 showed higher DNA protective activity than Trolox, despite its inferior activity in the DPPH assay (Table 1). Total $O$-alkylation or $O$-acylation of $\mathbf{1}$ destroyed the activity, as observed in the lost or diminished activity for 4, 7, 8, 9, 14, 15, 17, 19 and 20. The lost activity of 20 could be rescued by placing an $\mathrm{OH}$ substituent on ring $\mathrm{B}(27)$, an outcome similar to the case of the DPPH radical. The partially $O$-alkylated products of $\mathbf{1}$, including $3, \mathbf{1 0}$, and $\mathbf{1 1}$ showed enhanced DNA protective activity, but the tri-O-isopropylated product 6 displayed markedly reduced activity.

Compound 18 did not lose the DNA protective activity despite the removal of the $\mathrm{C}=\mathrm{C}$ bond. With the aid of the $\mathrm{C}=\mathrm{O}$ of the dihydro- $\alpha$-pyrone ring, this compound showed even higher activity than $\mathbf{1}$. The placement of the electron-donating group $\mathrm{OH}$ on ring A of $\mathbf{2 0}$ could restore the lost activity, giving 27, which is a better DNA protectant than 1 . The introduction of an electron-withdrawing substituent to the aromatic rings of $\mathbf{1}$ gave unclear results. Placing $\mathrm{Cl}$ on ring $\mathrm{B}$ (i.e., compound $\mathbf{1 2}$ ) slightly increased the activity, but introducing $\mathrm{COOH}$ onto ring A reduced the activity (compound 24).

\subsection{3. $\alpha$-Glucosidase Inhibitory Activity}

Almost all of the stilbenoids 2-27 prepared from oxyresveratrol exhibited reduced or lost inhibitory activity against $\alpha$-glucosidase (the positive control acarbose: $\mathrm{IC}_{50} 745.9 \pm 88.4 \mu \mathrm{M}$ ). The only exception was 6, which showed activity $\left(\mathrm{IC}_{50} 19.6 \pm 3.6 \mu \mathrm{M}\right)$ comparable to that of $\mathbf{1}\left(\mathrm{IC}_{50} 19.5 \pm\right.$ $1.7 \mu \mathrm{M})$. In a previous study, $\mathbf{1}$ has been suggested to be a promising structure for anti-diabetic drug development [7]. However, the compound, after oral absorption, was found to undergo extensive hepatic metabolism and rapid urinary elimination, resulting in a short half-life time $(\sim 0.96 \mathrm{~h})$ [21]. Compound 6, with three isopropoxy groups, is predicted to have much slower metabolism and may be considered as a better candidate for the preclinical and clinical studies for anti-DM drugs.

\subsubsection{Neuraminidase Inhibitory Activity}

In this study, oxyresveratol and all of its derivatives 2-27 exhibited no activity against the enzyme neuraminidase (positive control oseltamivir, $\mathrm{IC}_{50} 0.5 \mathrm{nM}$ ), although 1 has been earlier described as having modest activity [19]. It should be mentioned that resveratrol, a closely related stilbene, and several of its synthetic and semisynthetic analogs have been recently reported to possess significant inhibitory activity against influenza neuraminidase [28].

\subsubsection{Antiherpetic Activity}

Compounds 1-27 were first evaluated for anti-HSV-1 activity at $100 \mu \mathrm{g} / \mathrm{mL}$. Those that showed $>50 \%$ inhibition at this concentration were further studied to determine their $\mathrm{IC}_{50}$ values (Table 2).

Three analogs, including compounds $\mathbf{2 , 3}$, and $\mathbf{6}$, showed $\mathrm{IC}_{50}$ values significantly lower than that of $\mathbf{1}$. Stilbenes $\mathbf{2}$ and $\mathbf{3}$ (di- and tri-O-methylated products of $\mathbf{1}$ ) displayed 3- to 4-fold higher antiherpetic activity than the parent compound. Recently, compelling evidence has suggested that HSV-1 infection of neuronal and glial cells plays a pivotal role in the pathogenesis of Alzheimer's disease (AD), and the use of antiviral drugs in the treatment of $\mathrm{AD}$ has been proposed [13]. As mentioned earlier, 1, despite its moderate anti-herpetic activity in vitro, exhibited potent activity in vivo in mice cutaneously infected 
with HSV-1 [12].However, due to its poor BBB permeability [22], oxyresveratrol (1) seems to have limited clinical application. In this regard, stilbenes $\mathbf{2}$ and 3, with their higher lipophilicity, may be better candidates for further investigation on HSV infection of the CNS, as well as neurodegenerative diseases such as $\mathrm{AD}$ or PD.

Table 2. Anti-herpetic activity of $\mathbf{1}$ and derivatives.

\begin{tabular}{cc}
\hline Compounds & IC $_{\mathbf{5 0}}(\mu \mathbf{M})$ \\
\hline $\mathbf{1}$ & $147.1 \pm 16.8$ \\
$\mathbf{2}$ & $40.2 \pm 6.8^{*}$ \\
$\mathbf{3}$ & $32.8 \pm 5.9^{*}$ \\
$\mathbf{6}$ & $107.0 \pm 9.8^{*}$ \\
$\mathbf{1 0}$ & $182.3 \pm 28.9$ \\
$\mathbf{1 4}$ & $130.3 \pm 14.9$ \\
$\mathbf{1 5}$ & $123.5 \pm 19.3$ \\
$\mathbf{1 8}$ & $289.3 \pm 40.8^{*}$ \\
$\mathbf{2 1}$ & $188.3 \pm 25.1$ \\
$\mathbf{2 2}$ & $207.4 \pm 16.9^{*}$ \\
$\mathbf{2 3}$ & $344.7 \pm 32.5^{*}$ \\
$\mathbf{2 6}$ & $226.8 \pm 35.7^{*}$ \\
$\mathrm{ACV}$ & $1.6 \pm 0.0^{*}$ \\
\hline
\end{tabular}

* Significantly different from that of $\mathbf{1}(p<0.05)$.

\subsubsection{Cytotoxicity against Cancer Cells}

All compounds (1-27) were initially evaluated at $50 \mu \mathrm{g} / \mathrm{mL}$, and those demonstrating $>50 \%$ inhibition were subjected to $\mathrm{IC}_{50}$ determination (Table 3).

Table 3. Cytotoxicity against cancer cells of $\mathbf{1}$ and some derivatives.

\begin{tabular}{|c|c|c|c|c|}
\hline \multirow{2}{*}{ Compounds } & \multicolumn{4}{|c|}{$\mathrm{IC}_{50}(\mu \mathrm{M})$} \\
\hline & T47-D & HeLa & A549 & H69AR \\
\hline 1 & $152.7 \pm 4.5$ & $126.2 \pm 0.3$ & $159.8 \pm 0.0$ & nd \# \\
\hline 2 & $114.2 \pm 2.0 *$ & $28.4 \pm 7.0$ * & $117.0 \pm 11.1^{*}$ & $180.7 \pm 3.4$ \\
\hline 3 & $87.1 \pm 9.5 *$ & $13.1 \pm 2.1 *$ & $52.4 \pm 0.9 *$ & $36.7 \pm 3.3$ \\
\hline 4 & nd & $12.1 \pm 1.5^{*}$ & nd & $26.8 \pm 7.6$ \\
\hline 5 & $117.4 \pm 11.9 *$ & $11.0 \pm 2.7^{*}$ & $55.5 \pm 3.5$ * & $39.2 \pm 6.5$ \\
\hline 6 & $37.7 \pm 12.9 *$ & $25.7 \pm 2.1^{*}$ & $28.8 \pm 5.1 *$ & $54.5 \pm 3.0$ \\
\hline 8 & $103.0 \pm 4.3 *$ & nd & nd & nd \\
\hline 10 & $88.6 \pm 2.9 *$ & $100.9 \pm 4.7^{*}$ & $137.7 \pm 8.4^{*}$ & nd \\
\hline 12 & $156.6 \pm 6.0$ & $33.4 \pm 2.9 *$ & $120.7 \pm 2.9 *$ & $111.2 \pm 3.1$ \\
\hline 13 & nd & $18.7 \pm 4.2 *$ & nd & $65.7 \pm 3.2$ \\
\hline 14 & nd & $69.1 \pm 3.3^{*}$ & nd & nd \\
\hline 15 & $101.4 \pm 9.1 *$ & $83.2 \pm 9.1 *$ & nd & nd \\
\hline 16 & $99.3 \pm 3.1 *$ & $74.4 \pm 4.8^{*}$ & $138.0 \pm 3.1 *$ & nd \\
\hline 20 & $81.3 \pm 0.6$ * & $5.7 \pm 0.6^{*}$ & $51.7 \pm 1.7^{*}$ & $38.0 \pm 2.2$ \\
\hline 21 & $54.5 \pm 2.0 *$ & $18.9 \pm 0.7^{*}$ & $71.3 \pm 3.2 *$ & nd \\
\hline 23 & $82.9 \pm 2.2 *$ & $77.9 \pm 2.1^{*}$ & $143.2 \pm 3.3^{*}$ & nd \\
\hline 25 & $44.7 \pm 2.6^{*}$ & $22.4 \pm 0.4$ * & $75.1 \pm 0.7^{*}$ & $111.0 \pm 2.3$ \\
\hline 27 & $83.2 \pm 10.6^{*}$ & $79.8 \pm 4.7^{*}$ & $104.4 \pm 5.3 *$ & nd \\
\hline Doxorubicin & $0.5 \pm 0.00 *$ & $0.7 \pm 0.2 *$ & $0.4 \pm 0.1^{*}$ & $21.7 \pm 0.9$ \\
\hline
\end{tabular}

Seventeen derivatives demonstrated higher cytotoxicity than the parent compound $\mathbf{1}$, which was virtually non-cytotoxic against all cancer cell lines. The partially (di- or tri-) $O$-alkylated products (2, 3, 
5 and 6) showed increased cytotoxicity against all types of cancer cells. The fully $O$-methylated product 4 showed enhanced selective cytotoxicity against HeLa and H69AR cells, but no activity against T47-D and A549 cells. Interestingly, the $\mathrm{IC}_{50}$ value of 4 against the multidrug-resistant small lung cancer cells (H69AR) was in the same range as that of doxorubicin $(p>0.05)$. The fully $O$-isopropylated products, including $7,9,17$, and 19, did not show cytotoxicity in the assays, probably a result of their poor aqueous solubility. With regard to the esterified analogs, the fully $O$-acetylated compound $\mathbf{8}$ showed slightly improved activity selectively against T47-D cells, but less activity against HeLa and A549 cells when compared with $\mathbf{1}$. Compound 20, a di-O-isopropylated-di-O-acetylated product of $\mathbf{1}$, showed better cytotoxicity than $\mathbf{1}$ in all cancer cell lines, with selective potency against HeLa cells.

Different impacts on the cytotoxicity were observed when an electron-withdrawing substituent was attached to the aromatic rings of $\mathbf{1}$. Chlorination of $\mathbf{1}$ at $\mathrm{C}-2^{\prime}$ gave $\mathbf{1 2}$, a product with increased cytotoxicity against almost all cancer cell lines, except T47D cells. Similar cytotoxicity profiles were observed for compounds $\mathbf{1 6}$ and 23, the 5- and the $2^{\prime}$-formylated analogs, both of which displayed increased activity against T47-D, HeLa and A549, but no activity against H69AR cells. Further structural modification of $\mathbf{2 3}$ by converting the $\mathrm{CHO}$ into a $\mathrm{COOH}$ group (compound 24 ) destroyed the cytotoxicity in all cancer cell lines. When 7 , the fully $O$-isopropylated analog, was formylated or carboxylated at $\mathrm{C}-2^{\prime}$, partial restoration of cytotoxicity was observed (compounds 14 and 15). For 20, placing a $\mathrm{CHO}$ group at $\mathrm{C}-5$ gave a product $\mathbf{2 1}$ with mixed results since the cytotoxicity against TD47-D cells was enhanced, but the activity against HeLa A549 and H69AR cells was weakened $(p<0.05)$. Transforming the $\mathrm{CHO}$ at this position of $\mathbf{2 1}$ into a $\mathrm{COOH}$ group abolished the activity (compound 22). An electron-donating group such as hydroxy group, when added to the aromatic rings, could not induce cytotoxicity, as reflected from the non-cytotoxicity of both 7 and 17, but instead seemed to weaken the cytotoxicity, as evident when comparing the strong activity of $\mathbf{2 0}$ with that of $\mathbf{2 7}$ which showed less cytotoxicity in HeLa and A549 cancer cells $(p<0.05)$.

\section{Materials and Methods}

\subsection{General Information}

All chemical reagents were purchased from commercial suppliers. Melting points (uncorrected) were determined on a Fisher-Johns hot stage melting point apparatus. IR spectra were performed using Universal Attenuated Total Reflectance (UATR) on a 2000 FT-IR system (Perkin Elmer, Boston, MA, USA) or an A-30 spectrophotometer (Jasco, Easton, MD, USA). High resolution mass spectra were taken on a MicroTOF instrument (Bruker, Billerica, MA, USA) using atmospheric pressure chemical ionization (APCI) or electrospray ionization (ESI) in positive or negative mode. ${ }^{1} \mathrm{H}$ - and ${ }^{13} \mathrm{C}-\mathrm{NMR}$ were recorded on an Avance III $300 \mathrm{MHz}$ spectrometer or $400 \mathrm{MHz}$ spectrometer (Bruker, Billerica, MA, USA). All chemical shift values were reported as $\delta$ (ppm) and coupling constant values $J$ were measured in Hz. Oxyresveratrol (1) was isolated and purified from the heartwood of Artocarpus lacucha Buch.-Ham. (A. lakoocha Roxb.) as previously described [11,29,30].

\subsection{Synthesis}

\subsubsection{Preparation of Compounds $\mathbf{2}-\mathbf{4}$}

$\mathrm{K}_{2} \mathrm{CO}_{3}(680 \mathrm{mg}, 4.92 \mathrm{mmol})$ and $\mathrm{MeI}(0.11 \mathrm{~mL}, 1.8 \mathrm{mmol})$ were added to the solution of $\mathbf{1}(200 \mathrm{mg}$, $0.82 \mathrm{mmol}$ ) in acetone $(4 \mathrm{~mL})$ at room temperature. The reaction mixture was stirred overnight. Then, the reaction mixture was diluted with water $(5 \mathrm{~mL})$ and extracted with EtOAc $(3 \times 5 \mathrm{~mL})$. The EtOAc layer was washed with brine, dried over anhydrous $\mathrm{Na}_{2} \mathrm{SO}_{4}$, filtered and concentrated under reduced pressure to give a crude product which, after purification by preparative TLC (50\% EtOAc/hexanes), furnished 2 (19 $\mathrm{mg}, 9 \%), 3(60 \mathrm{mg}, 25 \%)$ and $4(112 \mathrm{mg}, 45 \%)$.

3',5'-Dihydroxy-2,4-dimethoxystilbene (2): viscous brown oil; IR (UATR, $\mathrm{cm}^{-1}$ ): 3374, 2931, 1601; ${ }^{1} \mathrm{H}-\mathrm{NMR}$ (300 MHz, CDCl $), \delta(\mathrm{ppm}): 7.43(\mathrm{~d}, J=8.4 \mathrm{~Hz}, 1 \mathrm{H}), 7.30(\mathrm{~d}, J=16.5 \mathrm{~Hz}, 1 \mathrm{H}), 6.82(\mathrm{~d}, J=16.2 \mathrm{~Hz}, 1 \mathrm{H})$, 
$6.55(\mathrm{~d}, J=2.1 \mathrm{~Hz}, 2 \mathrm{H}), 6.48(\mathrm{dd}, J=8.7,2.1 \mathrm{~Hz}, 1 \mathrm{H}), 6.44(\mathrm{~d}, J=2.1 \mathrm{~Hz}, 1 \mathrm{H}), 6.24(\mathrm{t}, J=2.1 \mathrm{~Hz}, 1 \mathrm{H})$, $3.82(\mathrm{~s}, 3 \mathrm{H}), 3.80(\mathrm{~s}, 3 \mathrm{H}) ;{ }^{13} \mathrm{C}-\mathrm{NMR}\left(75 \mathrm{MHz}, \mathrm{CDCl}_{3}\right), \delta(\mathrm{ppm}): 160.6,158.1,156.9,141.0,127.3,126.2$, 124.1, 119.2, 105.9, 105.1, 101.7, 98.5, 55.5, 55.4; TOF-HRMS $m / z$ [M + H] $]^{+}$, calcd for $\mathrm{C}_{16} \mathrm{H}_{17} \mathrm{O}_{4}$ : 273.1121; found: 273.1118 .

$5^{\prime}$-Hydroxy-2,3' $3^{\prime}$-trimethoxystilbene (3): viscous brown oil; IR (UATR, $\mathrm{cm}^{-1}$ ): 3408, 2938, 1590; ${ }^{1} \mathrm{H}-\mathrm{NMR}$ $\left(300 \mathrm{MHz}, \mathrm{CDCl}_{3}\right), \delta(\mathrm{ppm}): 7.46(\mathrm{~d}, J=8.4 \mathrm{~Hz}, 1 \mathrm{H}), 7.33(\mathrm{~d}, J=16.5 \mathrm{~Hz}, 1 \mathrm{H}), 6.88(\mathrm{~d}, J=16.5 \mathrm{~Hz}, 1 \mathrm{H})$, $6.62(\mathrm{~d}, J=1.8 \mathrm{~Hz}, 1 \mathrm{H}), 6.60(\mathrm{~d}, J=1.8 \mathrm{~Hz}, 1 \mathrm{H}), 6.49(\mathrm{dd}, J=8.4,2.4 \mathrm{~Hz}, 1 \mathrm{H}), 6.45(\mathrm{~d}, J=2.4 \mathrm{~Hz}, 1 \mathrm{H})$, $6.30(\mathrm{t}, J=2.1 \mathrm{~Hz}, 1 \mathrm{H}), 3.83(\mathrm{~s}, 3 \mathrm{H}), 3.81(\mathrm{~s}, 3 \mathrm{H}), 3.78(\mathrm{~s}, 3 \mathrm{H}) ;{ }^{13} \mathrm{C}-\mathrm{NMR}\left(75 \mathrm{MHz}, \mathrm{CDCl}_{3}\right), \delta(\mathrm{ppm})$ : 160.9, 160.5, 158.0, 156.9, 140.6, 127.3, 126.6, 123.9, 119.3, 105.8, 105.0, 104.6, 100.4, 98.5, 55.5, 55.4, 55.3; TOF-HRMS $\mathrm{m} / z[\mathrm{M}+\mathrm{H}]^{+}$, calcd for $\mathrm{C}_{17} \mathrm{H}_{19} \mathrm{O}_{4}$ : 287.1278; found: 287.1285 .

2,3' $3^{\prime} 4,5^{\prime}$-Tetramethoxystilbene (4): white solid, mp 65-68 ${ }^{\circ} \mathrm{C} ;{ }^{1} \mathrm{H}-\mathrm{NMR}\left(300 \mathrm{MHz}, \mathrm{CDCl}_{3}\right), \delta$ (ppm): 7.46 $(\mathrm{d}, J=8.4 \mathrm{~Hz}, 1 \mathrm{H}), 7.36(\mathrm{~d}, J=16.2 \mathrm{~Hz}, 1 \mathrm{H}), 6.92(\mathrm{~d}, J=16.5 \mathrm{~Hz}, 1 \mathrm{H}), 6.66(\mathrm{~d}, J=2.4 \mathrm{~Hz}, 2 \mathrm{H}), 6.47(\mathrm{dd}$, $J=8.4,2.4 \mathrm{~Hz}, 1 \mathrm{H}), 6.42(\mathrm{~d}, J=2.4 \mathrm{~Hz}, 1 \mathrm{H}), 6.34(\mathrm{t}, J=2.1 \mathrm{~Hz}, 1 \mathrm{H}), 3.81(\mathrm{~s}, 3 \mathrm{H}), 3.79(\mathrm{~s}, 6 \mathrm{H}), 3.77(\mathrm{~s}, 3 \mathrm{H})$; ${ }^{13} \mathrm{C}-\mathrm{NMR}\left(75 \mathrm{MHz}, \mathrm{CDCl}_{3}\right), \delta$ (ppm): 160.8, 160.5, 158.0, 140.3, 127.2, 126.8, 123.7, 119.1, 104.9, 104.2, 99.2, 98.3, 55.3, 55.2, 55.1; TOF-HRMS $m / z[\mathrm{M}+\mathrm{H}]^{+}$, calcd for $\mathrm{C}_{18} \mathrm{H}_{21} \mathrm{O}_{4}$ : 301.1434; found: 301.1440. The spectroscopic data were in agreement with previously reported values [9].

\subsubsection{Preparation of Compounds $5-7$}

To a solution of $\mathbf{1}(100 \mathrm{mg}, 0.41 \mathrm{mmol})$ in DMF $(2 \mathrm{~mL}), \mathrm{K}_{2} \mathrm{CO}_{3}(283 \mathrm{mg}, 2.05 \mathrm{mmol})$ and 2-bromopropane $(2.30 \mathrm{~mL}, 24.6 \mathrm{mmol})$ were added. Then 2-bromopropane $(1.15 \mathrm{~mL}, 12.3 \mathrm{mmol})$ was added every $24 \mathrm{~h}$. The reaction mixture was stirred at $55^{\circ} \mathrm{C}$ for 3 days and monitored by TLC. After completion, water $(5 \mathrm{~mL})$ was added, and the reaction was extracted with EtOAc $(3 \times 5 \mathrm{~mL})$. The organic phase was washed with water $(7 \times 5 \mathrm{~mL})$ and brine, dried over $\mathrm{Na}_{2} \mathrm{SO}_{4}$, filtered and concentrated. Column chromatographic purification with gradient EtOAc/hexanes $(10 \%$ EtOAc/hexanes $\rightarrow 80 \%$ EtOAc/hexanes) gave 5 (32 mg, 24\%), 6 (46 mg, 30\%) and 7 (47 mg, 28\%).

$3^{\prime}, 5^{\prime}$-Dihydroxy-2,4-diisopropoxystilbene (5): brown oil; IR (UATR, $\mathrm{cm}^{-1}$ ): 3379, 2976, 1598; ${ }^{1} \mathrm{H}-\mathrm{NMR}$ $\left(400 \mathrm{MHz}, \mathrm{CDCl}_{3}\right), \delta(\mathrm{ppm}): 7.43(\mathrm{~d}, J=8.4 \mathrm{~Hz}, 1 \mathrm{H}), 7.31(\mathrm{~d}, J=16.4 \mathrm{~Hz}, 1 \mathrm{H}), 6.84(\mathrm{~d}, J=16.4 \mathrm{~Hz}, 1 \mathrm{H})$, $6.56(\mathrm{~d}, J=2.1 \mathrm{~Hz}, 2 \mathrm{H}), 6.48(\mathrm{dd}, J=8.5,2.3 \mathrm{~Hz}, 1 \mathrm{H}), 6.45(\mathrm{~d}, J=2.2 \mathrm{~Hz}, 1 \mathrm{H}), 6.25(\mathrm{br} \mathrm{s}, 1 \mathrm{H}), 4.52(\mathrm{~m}$, $2 \mathrm{H}), 1.35(\mathrm{~d}, J=6 \mathrm{~Hz}, 6 \mathrm{H}), 1.33(\mathrm{~d}, J=6 \mathrm{~Hz}, 6 \mathrm{H}) ;{ }^{13} \mathrm{C}-\mathrm{NMR}\left(100 \mathrm{MHz}, \mathrm{CDCl}_{3}\right), \delta(\mathrm{ppm}): 158.6,157.0$, 156.5, 141.0, 127.4, 126.1, 124.3, 120.3, 107.5, 105.8, 103.2, 101.7, 71.2, 70.1, 22.1, 22.0; TOF-HRMS m/z $[\mathrm{M}-\mathrm{H}]^{-}$, calcd for $\mathrm{C}_{20} \mathrm{H}_{23} \mathrm{O}_{4}$ : 327.1602; found: 327.1594.

$5^{\prime}$-Hydroxy-2,3' $3^{\prime}$,-triisopropoxystilbene (6): brown oil; IR (UATR, $\mathrm{cm}^{-1}$ ): 3393, 2976, 1588; ${ }^{1} \mathrm{H}-\mathrm{NMR}(400$ $\left.\mathrm{MHz}, \mathrm{CDCl}_{3}\right), \delta(\mathrm{ppm}): 7.45(\mathrm{~d}, J=8.5 \mathrm{~Hz}, 1 \mathrm{H}), 7.32(\mathrm{~d}, J=16.4 \mathrm{~Hz}, 1 \mathrm{H}), 6.88(\mathrm{~d}, J=16.4 \mathrm{~Hz}, 1 \mathrm{H}), 6.61$ $(\mathrm{t}, J=1.5 \mathrm{~Hz}, 1 \mathrm{H}), 6.56(\mathrm{t}, J=1.6 \mathrm{~Hz}, 1 \mathrm{H}), 6.49(\mathrm{dd}, J=8.5,2.3 \mathrm{~Hz}, 1 \mathrm{H}), 6.46(\mathrm{~d}, J=2.3 \mathrm{~Hz}, 1 \mathrm{H}), 6.28(\mathrm{t}$, $J=2.1 \mathrm{~Hz}, 1 \mathrm{H}), 4.534(\mathrm{~m}, 2 \mathrm{H}), 4.527(\mathrm{~m}, 1 \mathrm{H}), 1.37(\mathrm{~d}, J=6 \mathrm{~Hz}, 6 \mathrm{H}), 1.343(\mathrm{~d}, J=6 \mathrm{~Hz}, 6 \mathrm{H}), 1.336(\mathrm{~d}$, $J=6 \mathrm{~Hz}, 6 \mathrm{H}) ;{ }^{13} \mathrm{C}-\mathrm{NMR}\left(100 \mathrm{MHz}, \mathrm{CDCl}_{3}\right), \delta$ (ppm): 159.2, 158.6, 156.7, 156.5, 140.8, 127.4, 126.2, 124.4, $120.2,107.4,107.0,105.4,103.0,101.8,71.0,70.0,69.9,22.2,22.0$; TOF-HRMS $m / z[M-H]^{-}$, calcd for $\mathrm{C}_{23} \mathrm{H}_{29} \mathrm{O}_{4}$ : 369.2071; found: 369.2066 .

2,3' $, 4,5^{\prime}$-Tetraisopropoxystilbene (7): white solid, mp 58-60 ${ }^{\circ} \mathrm{C}$; IR (UATR, $\mathrm{cm}^{-1}$ ): 2976, $1585 ;{ }^{1} \mathrm{H}-\mathrm{NMR}$ $\left(300 \mathrm{MHz}, \mathrm{CDCl}_{3}\right), \delta(\mathrm{ppm}): 7.46(\mathrm{~d}, J=8.4 \mathrm{~Hz}, 1 \mathrm{H}), 7.33(\mathrm{~d}, J=16.4 \mathrm{~Hz}, 1 \mathrm{H}), 6.91(\mathrm{~d}, J=16.4 \mathrm{~Hz}, 1 \mathrm{H})$, $6.62(\mathrm{~d}, J=2.2 \mathrm{~Hz}, 2 \mathrm{H}), 6.49(\mathrm{dd}, J=8.5,2.3 \mathrm{~Hz}, 1 \mathrm{H}), 6.45(\mathrm{~d}, J=3.9 \mathrm{~Hz}, 1 \mathrm{H}), 6.34(\mathrm{t}, J=2.1 \mathrm{~Hz}, 1 \mathrm{H})$, $4.55(\mathrm{~m}, 4 \mathrm{H}), 1.37(\mathrm{~d}, J=6 \mathrm{~Hz}, 6 \mathrm{H}), 1.35(\mathrm{~d}, J=6 \mathrm{~Hz}, 12 \mathrm{H}), 1.34(\mathrm{~d}, J=6 \mathrm{~Hz}, 6 \mathrm{H}),{ }^{13} \mathrm{C}-\mathrm{NMR}(75 \mathrm{MHz}$, $\left.\mathrm{CDCl}_{3}\right), \delta$ (ppm): 159.1, 158.6, 156.6, 140.5, 127.4, 126.7, 124.2, 120.4, 107.3, 106.4, 103.0, 102.5, 71.0, 69.9, 69.8, 22.2, 22.1; TOF-HRMS $m / z[\mathrm{M}+\mathrm{H}]^{+}$, calcd for $\mathrm{C}_{26} \mathrm{H}_{37} \mathrm{O}_{4}$ : 413.2686; found: 413.2679.

\subsubsection{Preparation of $2,3^{\prime}, 4,5^{\prime}$-Tetraacetoxystilbene (8)}

Compound 8 was prepared as previously described [31]. To a well-stirred solution of $\mathbf{1}$ (50 $\mathrm{mg}$, $0.21 \mathrm{mmol})$ in $\mathrm{CH}_{2} \mathrm{Cl}_{2}(2 \mathrm{~mL}), \mathrm{Et}_{3} \mathrm{~N}(0.17 \mathrm{~mL}, 1.23 \mathrm{mmol})$, DMAP (63 mg, $\left.0.51 \mathrm{mmol}\right)$ and acetyl 
chloride $(0.04 \mathrm{~mL}, 0.61 \mathrm{mmol})$ were added at room temperature, and the reaction mixture was stirred for $3 \mathrm{~h}$. After completion of the reaction, it was extracted with EtOAc $(3 \times 5 \mathrm{~mL})$. The EtOAc layer was washed with brine, dried over $\mathrm{Na}_{2} \mathrm{SO}_{4}$, filtered and concentrated under reduced pressure to give a crude product. Purification with column chromatography eluting with $40 \%$ EtOAc/hexanes gave 8 (60 mg, 70\%). White solid, mp 129-131 ${ }^{\circ} \mathrm{C}$; IR (UATR, $\left.\mathrm{cm}^{-1}\right)$ : 1762, $1605 ;{ }^{1} \mathrm{H}-\mathrm{NMR}\left(300 \mathrm{MHz}, \mathrm{CDCl}_{3}\right)$, $\delta(\mathrm{ppm}): 7.61(\mathrm{~d}, J=8.7 \mathrm{~Hz}, 1 \mathrm{H}), 7.08(\mathrm{~d}, J=2.1 \mathrm{~Hz}, 2 \mathrm{H}), 7.05(\mathrm{~d}, J=15.9 \mathrm{~Hz}, 1 \mathrm{H}), 7.03(\mathrm{dd}, J=8.4$, $2.4 \mathrm{~Hz}, 1 \mathrm{H}), 6.97(\mathrm{~d}, J=15.9 \mathrm{~Hz}, 1 \mathrm{H}), 6.95(\mathrm{~d}, J=2.1 \mathrm{~Hz}, 1 \mathrm{H}), 6.85(\mathrm{t}, J=2.1 \mathrm{~Hz}, 1 \mathrm{H}), 2.36(\mathrm{~s}, 3 \mathrm{H}), 2.31(\mathrm{~s}$, 6H), 2.29 (s, 3H); ${ }^{13} \mathrm{C}-\mathrm{NMR}\left(75 \mathrm{MHz}, \mathrm{CDCl}_{3}\right), \delta$ (ppm): 168.93, 168.89, 168.8, 151.3, 150.5, 148.5, 139.4, $129.5,127.2,127.1,123.5,119.5,117.0,116.4,114.8,21.10,21.09,20.99 ;$ TOF-HRMS m/z [M + Na ${ }^{+}$, calcd for $\mathrm{C}_{22} \mathrm{H}_{20} \mathrm{NaO}_{8}$ : 435.1056; found: 435.1050. The spectroscopic data were in agreement with earlier reported values [32].

\subsubsection{Preparation of $3^{\prime}-O-C a r b e t h o x y m e t h y l-2,4,5^{\prime}$-triisopropoxystilbene (9)}

To a solution of $6(100 \mathrm{mg}, 0.27 \mathrm{mmol})$ in DMF $(4 \mathrm{~mL}), \mathrm{K}_{2} \mathrm{CO}_{3}(56 \mathrm{mg}, 0.40 \mathrm{mmol})$ and ethyl bromoacetate $(0.04 \mathrm{~mL}, 0.4 \mathrm{mmol})$ were added at room temperature, and the reaction mixture was stirred overnight. After completion of the reaction, water $(5 \mathrm{~mL})$ was added and the mixture was extracted with EtOAc $(3 \times 5 \mathrm{~mL})$. The organic layer was washed with water $(7 \times 5 \mathrm{~mL})$ and brine, dried over $\mathrm{Na}_{2} \mathrm{SO}_{4}$, filtered and concentrated under reduced pressure to give a crude product, which was purified by column chromatography on silica (15\% EtOAc/hexanes) to furnish 9 (103 mg, 84\%). Light brown oil; IR (UATR, $\mathrm{cm}^{-1}$ ): 2977, 1760, 1588; ${ }^{1} \mathrm{H}-\mathrm{NMR}\left(300 \mathrm{MHz}, \mathrm{CDCl}_{3}\right), \delta$ (ppm): 7.45 (d, $J=8.4 \mathrm{~Hz}, 1 \mathrm{H}), 7.33(\mathrm{~d}, J=16.5 \mathrm{~Hz}, 1 \mathrm{H}), 6.90(\mathrm{~d}, J=16.5 \mathrm{~Hz}, 1 \mathrm{H}), 6.68(\mathrm{~d}, J=1.5 \mathrm{~Hz}, 1 \mathrm{H}), 6.62(\mathrm{~d}$, $J=1.8 \mathrm{~Hz}, 1 \mathrm{H}), 6.48(\mathrm{dd}, J=8.7,2.4 \mathrm{~Hz}, 1 \mathrm{H}), 6.45(\mathrm{~d}, J=2.1 \mathrm{~Hz}, 1 \mathrm{H}), 6.36(\mathrm{t}, J=2.2 \mathrm{~Hz}, 1 \mathrm{H}), 4.62(\mathrm{~s}, 2 \mathrm{H})$, $4.54(\mathrm{~m}, 3 \mathrm{H}), 4.26(\mathrm{q}, J=7.1 \mathrm{~Hz}, 2 \mathrm{H}), 1.38(\mathrm{~d}, J=6 \mathrm{~Hz}, 6 \mathrm{H}), 1.344(\mathrm{~d}, J=6 \mathrm{~Hz}, 6 \mathrm{H}), 1.339(\mathrm{~d}, J=6 \mathrm{~Hz}$, $6 \mathrm{H}), 1.30(\mathrm{t}, J=6.8 \mathrm{~Hz}, 3 \mathrm{H}) ;{ }^{13} \mathrm{C}-\mathrm{NMR}\left(75 \mathrm{MHz} \mathrm{CDCl}_{3}\right), \delta(\mathrm{ppm}): 168.9,159.0,158.7,156.6,140.7,127.4$, $126.3,124.6,120.1,107.6,107.3,104.7,102.9,101.4,70.9,69.9,65.5,61.8,61.3,22.1,22.0,14.1$; TOF-HRMS $m / z[\mathrm{M}+\mathrm{Na}]^{+}$, calcd for $\mathrm{C}_{27} \mathrm{H}_{36} \mathrm{NaO}_{6}: 479.2404$; found: 479.2388 .

\subsubsection{Preparation of 3'-O-Carbethoxymethyl-2,4,5'-trihydroxystilbene (10)}

A solution of $\mathrm{BCl}_{3}(3.07 \mathrm{~mL}, 3.07 \mathrm{mmol})$ was added to a solution of $9(233 \mathrm{mg}, 0.51 \mathrm{mmol})$ in $\mathrm{CH}_{2} \mathrm{Cl}_{2}(8 \mathrm{~mL})$ at $-78{ }^{\circ} \mathrm{C}$ under argon. Then it was allowed to warm to room temperature and stirred overnight. The reaction mixture was quenched with water $(10 \mathrm{~mL})$ and then extracted with EtOAc $(3 \times 10 \mathrm{~mL})$. The organic phase was washed with brine, dried over $\mathrm{Na}_{2} \mathrm{SO}_{4}$, filtered and concentrated under reduced pressure to give a crude product which was purified by preparative TLC (50\% EtOAc/hexanes) to give 10 (102 mg, 61\%). Pale yellow solid, mp 198-200 ${ }^{\circ} \mathrm{C}$; IR (UATR, $\mathrm{cm}^{-1}$ ): 3369, 1731, 1591; ${ }^{1} \mathrm{H}-\mathrm{NMR}\left(300 \mathrm{MHz}\right.$, acetone- $\left.d_{6}\right), \delta(\mathrm{ppm}): 7.43(\mathrm{~d}, J=8.4 \mathrm{~Hz}, 1 \mathrm{H}), 7.36(\mathrm{~d}, J=16.5 \mathrm{~Hz}$, $1 \mathrm{H}), 6.97(\mathrm{~d}, J=16.5 \mathrm{~Hz}, 1 \mathrm{H}), 6.70($ br s,1H), $6.63($ br s,1H), $6.49(\mathrm{~d}, J=2.1 \mathrm{~Hz}, 1 \mathrm{H}), 6.49$ (br s, $1 \mathrm{H}), 6.43$ $(\mathrm{dd}, J=8.4,2.1 \mathrm{~Hz}, 1 \mathrm{H}), 6.34(\mathrm{t}, J=2.1 \mathrm{~Hz}, 1 \mathrm{H}), 4.70(\mathrm{~s}, 2 \mathrm{H}), 4.21(\mathrm{q}, J=6.9 \mathrm{~Hz}, 2 \mathrm{H}), 1.25(\mathrm{t}, J=6.9 \mathrm{~Hz}$, $3 \mathrm{H}) ;{ }^{13} \mathrm{C}-\mathrm{NMR}\left(75 \mathrm{MHz}\right.$, acetone- $\left.d_{6}\right), \delta$ (ppm): 169.4, 160.4, 159.4, 159.1, 156.9, 141.7, 128.4, 126.0, 124.9, 117.1, 108.4, 107.1, 104.4, 103.5, 101.6, 65.8, 61.3, 14.4; TOF-HRMS m/z [M + Na $]^{+}$, calcd for $\mathrm{C}_{18} \mathrm{H}_{18} \mathrm{NaO}_{6}$ : 353.0996; found: 353.0989 .

\subsubsection{Preparation of 3'-O-Carboxymethyl-2,4,5'-trihydroxystilbene (11)}

To 10 (13 mg, $0.03 \mathrm{mmol}), \mathrm{KOH}(5 \%$ in $\mathrm{EtOH}, 1 \mathrm{~mL})$ was added at room temperature, and the reaction mixture was stirred for $10 \mathrm{~min}$. The reaction was acidified with $2 \mathrm{~N} \mathrm{HCl}$ to $\mathrm{pH}$. The material was extracted with EtOAc $(3 \times 5 \mathrm{~mL})$, and the combined organic layers were dried over $\mathrm{Na}_{2} \mathrm{SO}_{4}$, filtered, and concentrated under reduced pressure to provide 11 ( $3 \mathrm{mg}, 40 \%$ ). Brown solid; IR (UATR, $\mathrm{cm}^{-1}$ ): 3322, 2921, 2851, 1713; ${ }^{1} \mathrm{H}-\mathrm{NMR}\left(300 \mathrm{MHz}\right.$, methanol- $\left.d_{4}\right), \delta(\mathrm{ppm}): 7.33(\mathrm{~d}, J=8.9 \mathrm{~Hz}, 1 \mathrm{H}), 7.30$ $(\mathrm{d}, J=16.4 \mathrm{~Hz}, 1 \mathrm{H}), 6.86(\mathrm{~d}, J=16.4 \mathrm{~Hz}, 1 \mathrm{H}), 6.58(\mathrm{~d}, J=1.6 \mathrm{~Hz}, 1 \mathrm{H}), 6.56(\mathrm{~d}, J=1.8 \mathrm{~Hz}, 1 \mathrm{H}), 6.31(\mathrm{dd}$, $J=5.9,2.3 \mathrm{~Hz}, 1 \mathrm{H}), 6.30(\mathrm{~s}, 1 \mathrm{H}), 6.25(\mathrm{t}, J=2.1 \mathrm{~Hz}, 1 \mathrm{H}), 4.63(\mathrm{~s}, 2 \mathrm{H}) ;{ }^{13} \mathrm{C}-\mathrm{NMR}\left(75 \mathrm{MHz}\right.$, methanol- $\left.d_{4}\right), \delta$ 
(ppm):172.9, 160.8, 159.7, 159.4, 157.4, 142.4, 128.5, 126.2, 125.4, 117.7, 108.4, 107.3, 104.8, 103.6, 101.7, 65.9; TOF-HRMS $m / z$ [M $-\mathrm{H}]^{-}$, calcd for $\mathrm{C}_{16} \mathrm{H}_{13} \mathrm{O}_{6}$ : 301.0718; found: 301.0708.

3.2.7. Preparation of $2^{\prime}$-Chloro-2, $3^{\prime}, 4,5^{\prime}$-tetrahydroxystilbene (12)

A mixture of 1 (100 mg, $0.41 \mathrm{mmol})$ and $N$-chlorosuccinimide $(54.8 \mathrm{mg}, 0.41 \mathrm{mmol}$ ) in glacial acetic acid $(4 \mathrm{~mL})$ was stirred at room temperature under argon for $3 \mathrm{~h}$. After completion, solvent was removed under reduced pressure. Purification by column chromatography $\left(10 \% \mathrm{MeOH} / \mathrm{CH}_{2} \mathrm{Cl}_{2}\right)$ gave of 12 (42 mg, 36\% yield). Light brown solid, mp 185-187 ${ }^{\circ} \mathrm{C}$; IR (UATR, $\mathrm{cm}^{-1}$ ): 3196, $1599 ;{ }^{1} \mathrm{H}-\mathrm{NMR}$ $\left(300 \mathrm{MHz}\right.$, acetone- $\left.d_{6}\right), \delta(\mathrm{ppm}): 7.44(\mathrm{~d}, J=8.4 \mathrm{~Hz}, 1 \mathrm{H}), 7.38(\mathrm{~d}, J=16.4 \mathrm{~Hz}, 1 \mathrm{H}), 7.32(\mathrm{~d}, J=16.4 \mathrm{~Hz}$, $1 \mathrm{H}), 6.78(\mathrm{~d}, J=2.7 \mathrm{~Hz}, 1 \mathrm{H}), 6.45(\mathrm{~d}, J=2.4 \mathrm{~Hz}, 1 \mathrm{H}), 6.43(\mathrm{~d}, J=2.7 \mathrm{~Hz}, 1 \mathrm{H}), 6.41(\mathrm{dd}, J=8.4,2.4 \mathrm{~Hz}, 1 \mathrm{H})$; ${ }^{13} \mathrm{C}-\mathrm{NMR}\left(75 \mathrm{MHz}\right.$, acetone- $\left.d_{6}\right), \delta(\mathrm{ppm}): 158.6,156.5,156.3,153.9,137.9,127.9,126.3,121.3,116.2,110.4$, 107.6, 103.8, 102.7, 102.3; TOF-HRMS $m / z$ [M + H] ${ }^{+}$, calcd for $\mathrm{C}_{14} \mathrm{H}_{12} \mathrm{ClO}_{4}$ : 279.0419; found: 279.0408 .

\subsubsection{Preparation of $2^{\prime}$-Chloro- $2,3^{\prime}, 4,5^{\prime}$-tetramethoxystilbene (13)}

To a well-stirred solution of $12(88 \mathrm{mg}, 0.3 \mathrm{mmol})$ in acetone $(15 \mathrm{~mL}), \mathrm{K}_{2} \mathrm{CO}_{3}(265 \mathrm{mg}, 1.92 \mathrm{mmol})$ and $\mathrm{MeI}(0.11 \mathrm{~mL}, 1.8 \mathrm{mmol})$ were added. The reaction mixture was stirred at $55^{\circ} \mathrm{C}$ overnight and monitored by TLC. After completion of the reaction, the mixture was diluted with water $(10 \mathrm{~mL})$, and extracted with EtOAc $(3 \times 10 \mathrm{~mL})$. The organic phase was washed with brine. The organic extract was dried over $\mathrm{Na}_{2} \mathrm{SO}_{4}$, filtered and evaporated in vacuo. The residue obtained was purified over silica gel using 20\% EtOAc/hexanes to furnish $13\left(40 \mathrm{mg}, 36 \%\right.$ ). White solid; ${ }^{1} \mathrm{H}-\mathrm{NMR}\left(300 \mathrm{MHz}, \mathrm{CDCl}_{3}\right), \delta$ (ppm): $7.56(\mathrm{~d}, J=8.4 \mathrm{~Hz}, 1 \mathrm{H}), 7.44(\mathrm{~d}, J=16.5 \mathrm{~Hz}, 1 \mathrm{H}), 7.33(\mathrm{~d}, J=16.5 \mathrm{~Hz}, 1 \mathrm{H}), 6.83(\mathrm{~d}, J=2.7 \mathrm{~Hz}, 1 \mathrm{H})$, $6.52(\mathrm{dd}, J=8.7,2.1 \mathrm{~Hz}, 1 \mathrm{H}), 6.46(\mathrm{~d}, J=2.1 \mathrm{~Hz}, 1 \mathrm{H}), 6.42(\mathrm{t}, J=2.7 \mathrm{~Hz}, 1 \mathrm{H}), 3.87(\mathrm{~s}, 3 \mathrm{H}), 3.86(\mathrm{~s}, 3 \mathrm{H})$, $3.85(\mathrm{~s}, 3 \mathrm{H}), 3.83(\mathrm{~s}, 3 \mathrm{H}) ;{ }^{13} \mathrm{C}-\mathrm{NMR}\left(75 \mathrm{MHz}, \mathrm{CDCl}_{3}\right), \delta(\mathrm{ppm}): 160.9,158.6,158.2,155.9,137.7,127.7$, $126.0,123.2,119.2,113.8,105.0,101.9,98.6,98.4,56.2,55.6,55.5,55.4$; TOF-HRMS $\mathrm{m} / z[\mathrm{M}]^{+}$, calcd for $\mathrm{C}_{18} \mathrm{H}_{20} \mathrm{ClO}_{4}$ : 335.1045; found: 335.1035 .

\subsubsection{Preparation of $2^{\prime}$-Formyl-2, $3^{\prime}, 4,5^{\prime}$-tetraisopropoxystilbene (14)}

$\mathrm{POCl}_{3}(0.16 \mathrm{~mL}, 1.69 \mathrm{mmol})$ was stirred with dry DMF $(4 \mathrm{~mL})$ at room temperature for $2 \mathrm{~h}$ under argon. A solution of $7(200 \mathrm{mg}, 0.48 \mathrm{mmol})$ in dry DMF $(4 \mathrm{~mL})$ was added at $0{ }^{\circ} \mathrm{C}$ and the reaction mixture was further stirred overnight. After completion of the reaction, cool water $(10 \mathrm{~mL})$ was added, and the mixture was extracted with EtOAc $(3 \times 10 \mathrm{~mL})$. The organic layer was washed with water $(7 \times 10 \mathrm{~mL})$ and brine, dried over $\mathrm{Na}_{2} \mathrm{SO}_{4}$, filtered and concentrated under reduced pressure to give a crude product, which was purified by column chromatography on silica (15\% EtOAc/hexanes) to furnish 14 (171 mg, 80\%). Viscous yellow oil; IR (UATR, $\left.\mathrm{cm}^{-1}\right)$ : 2976, 1671, 1586; ${ }^{1} \mathrm{H}-\mathrm{NMR}(300 \mathrm{MHz}$, $\left.\mathrm{CDCl}_{3}\right), \delta(\mathrm{ppm}): 10.53(\mathrm{~s}, 1 \mathrm{H}), 8.08(\mathrm{~d}, J=16.4 \mathrm{~Hz}, 1 \mathrm{H}), 7.60(\mathrm{~d}, J=8.6 \mathrm{~Hz}, 1 \mathrm{H}), 7.30(\mathrm{~d}, J=16.4 \mathrm{~Hz}, 1 \mathrm{H})$, $6.75(\mathrm{~d}, J=2.1 \mathrm{~Hz}, 1 \mathrm{H}), 6.50(\mathrm{dd}, J=8.6,2.3 \mathrm{~Hz}, 1 \mathrm{H}), 6.44(\mathrm{~d}, J=2.4 \mathrm{~Hz}, 1 \mathrm{H}), 6.35(\mathrm{~d}, J=2.1 \mathrm{~Hz}, 1 \mathrm{H})$, 4.69 (sept, $J=6 \mathrm{~Hz}, 1 \mathrm{H}), 4.48-4.63(\mathrm{~m}, 3 \mathrm{H}), 1.33-1.41(\mathrm{~m}, 24 \mathrm{H}) ;{ }^{13} \mathrm{C}-\mathrm{NMR}\left(75 \mathrm{MHz}, \mathrm{CDCl}_{3}\right), \delta(\mathrm{ppm})$ : 191.1, 163.6, 162.7, 158.9, 156.7, 143.9, 128.1, 127.3, 125.4, 120.4, 116.8, 107.4, 105.0, 102.9, 100.1, 71.4, 70.9, 70.1, 69.9, 22.2, 22.04, 21.98; TOF-HRMS $m / z[\mathrm{M}+\mathrm{H}]^{+}$, calcd for $\mathrm{C}_{27} \mathrm{H}_{37} \mathrm{O}_{5}: 441.2635$; found: 441.2639.

\subsubsection{Preparation of $2^{\prime}$-Carboxy-2, $3^{\prime}, 4,5^{\prime}$-tetraisopropoxystilbene (15)}

A solution of $\mathrm{NaClO}_{2}(260 \mathrm{mg}, 2.88 \mathrm{mmol})$ and $\mathrm{NaH}_{2} \mathrm{PO}_{4} \cdot 2 \mathrm{H}_{2} \mathrm{O}(447 \mathrm{mg}, 2.86 \mathrm{mmol})$ in water $(1.5 \mathrm{~mL})$ was added to the solution of $14(157 \mathrm{mg}, 0.36 \mathrm{mmol})$ and 2-methyl-2-butene $(0.13 \mathrm{~mL}, 1.5 \mathrm{mmol})$ in acetone $(1.5 \mathrm{~mL})$ at room temperature. The reaction mixture was stirred for $1 \mathrm{~h}$. After completion, water $(5 \mathrm{~mL})$ was added, and the reaction mixture was extracted with EtOAc $(3 \times 5 \mathrm{~mL})$. The EtOAc phase was washed with brine, dried over $\mathrm{Na}_{2} \mathrm{SO}_{4}$, filtered and concentrated under reduced pressure to give crude product, which was purified by column chromatography on silica (40\% EtOAc/hexanes) to furnish 15 (129 mg, 79\%). Pale yellow solid, mp 154-156 ${ }^{\circ} \mathrm{C}$; IR (UATR, $\mathrm{cm}^{-1}$ ): 2976, 1730, 1697, 1592; ${ }^{1} \mathrm{H}-\mathrm{NMR}\left(300 \mathrm{MHz}, \mathrm{CDCl}_{3}\right), \delta(\mathrm{ppm}): 7.85(\mathrm{~d}, J=16.2 \mathrm{~Hz}, 1 \mathrm{H}), 7.56(\mathrm{~d}, J=8.4 \mathrm{~Hz}, 1 \mathrm{H}), 7.19(\mathrm{~d}$, $J=16.2 \mathrm{~Hz}, 1 \mathrm{H}), 6.85(\mathrm{~d}, J=2.1 \mathrm{~Hz}, 1 \mathrm{H}), 6.49(\mathrm{dd}, J=8.4,2.1 \mathrm{~Hz}, 1 \mathrm{H}), 6.44(\mathrm{~d}, J=2.1 \mathrm{~Hz}, 1 \mathrm{H}), 6.42$ 
$(\mathrm{d}, J=2.1 \mathrm{~Hz}, 1 \mathrm{H}), 4.68(\mathrm{~m}, 2 \mathrm{H}), 4.54(\mathrm{~m}, 2 \mathrm{H}), 1.44(\mathrm{~d}, J=6.3 \mathrm{~Hz}, 6 \mathrm{H}), 1.40(\mathrm{~d}, J=6.3 \mathrm{~Hz}, 6 \mathrm{H}), 1.37$ $(\mathrm{d}, J=6.3 \mathrm{~Hz}, 6 \mathrm{H}), 1.34(\mathrm{~d}, J=6 \mathrm{~Hz}, 6 \mathrm{H}) ;{ }^{13} \mathrm{C}-\mathrm{NMR}\left(75 \mathrm{MHz}, \mathrm{CDCl}_{3}\right), \delta$ (ppm): 166.0, 160.9, 158.8, 158.0, 156.6, 145.6, 128.1, 126.6, 126.5, 120.4, 107.4, 103.0, 101.5, 74.1, 71.0, 70.2, 70.0, 22.2, 22.1, 22.0, 21.9; TOF-HRMS $m / z[\mathrm{M}+\mathrm{H}]^{+}$, calcd for $\mathrm{C}_{27} \mathrm{H}_{37} \mathrm{O}_{6}: 457.2585$; found: 457.2587 .

\subsubsection{Preparation of $2^{\prime}$-Formyl-2, $3^{\prime}, 4,5^{\prime}$-tetrahydroxystilbene (16)}

A solution of $\mathrm{BCl}_{3}(2.17 \mathrm{~mL}, 2.17 \mathrm{mmol})$ was added to a solution of $14(119 \mathrm{mg}, 0.27 \mathrm{mmol})$ in $\mathrm{CH}_{2} \mathrm{Cl}_{2}(4 \mathrm{~mL})$ at $-78{ }^{\circ} \mathrm{C}$ under argon. The reaction was allowed to warm up to room temperature and stirred overnight. Then, water $(5 \mathrm{~mL})$ was added, and the reaction was extracted with EtOAc $(3 \times 5 \mathrm{~mL})$. The EtOAc layer was washed with brine, dried over $\mathrm{Na}_{2} \mathrm{SO}_{4}$, filtered and concentrated under reduced pressure to give a crude product which was purified by using preparative TLC ( $40 \%$ EtOAc/hexanes) to give $\mathbf{1 6}$ (35 mg, 48\%). Yellow solid, decomposed $>218^{\circ} \mathrm{C}$; IR (UATR, $\mathrm{cm}^{-1}$ ): 3337 , 1602; ${ }^{1} \mathrm{H}-\mathrm{NMR}\left(300 \mathrm{MHz}\right.$, methanol- $\left.d_{4}\right), \delta(\mathrm{ppm}): 10.17(\mathrm{~s}, 1 \mathrm{H}), 7.55(\mathrm{~d}, J=15.9 \mathrm{~Hz}, 1 \mathrm{H}), 7.38(\mathrm{~d}$, $J=9 \mathrm{~Hz}, 1 \mathrm{H}), 7.23(\mathrm{~d}, J=15.9 \mathrm{~Hz}, 1 \mathrm{H}), 6.56(\mathrm{~d}, J=2 \mathrm{~Hz}, 1 \mathrm{H}), 6.33(\mathrm{dd}, J=8.6,2.3 \mathrm{~Hz}, 1 \mathrm{H}), 6.32(\mathrm{br} \mathrm{s}$, $1 \mathrm{H}), 6.14(\mathrm{~d}, J=2 \mathrm{~Hz}, 1 \mathrm{H}) ;{ }^{13} \mathrm{C}-\mathrm{NMR}\left(75 \mathrm{MHz}\right.$, methanol- $\left.d_{4}\right), \delta(\mathrm{ppm}): 194.3,167.3,167.2,160.1,158.0$, 148.0, 131.8, 129.6, 120.4, 117.2, 112.8, 108.5, 107.4, 103.6, 102.0; TOF-HRMS $m / z$ [M - H] ${ }^{-}$, calcd for $\mathrm{C}_{15} \mathrm{H}_{11} \mathrm{O}_{5}$ : 271.0612; found: 271.0607 .

\subsubsection{Preparation of $2^{\prime}$-Hydroxy-2,3' $, 4,5^{\prime}$-tetraisopropoxystilbene (17)}

Compound $14(121 \mathrm{mg}, 0.27 \mathrm{mmol})$ and $p-\mathrm{TsOH} \cdot \mathrm{H}_{2} \mathrm{O}(15 \mathrm{mg}, 0.09 \mathrm{mmol})$ were dissolved in methanol $(1 \mathrm{~mL})$. Then $30 \%$ hydrogen peroxide $(0.07 \mathrm{~mL}, 0.54 \mathrm{mmol})$ was added at $0{ }^{\circ} \mathrm{C}$, and the reaction was then warmed to room temperature and stirred for $1 \mathrm{~h}$. Half-saturated sodium sulfite solution $(1 \mathrm{~mL})$ was added, and the mixture was extracted with $\mathrm{CH}_{2} \mathrm{Cl}_{2}(3 \times 5 \mathrm{~mL})$. The organic phase was washed with brine, dried over $\mathrm{Na}_{2} \mathrm{SO}_{4}$, filtered and concentrated under reduced pressure to give a crude product. Purification with preparative TLC (10\% EtOAc/hexanes) gave 17 (78 mg, 66\%). Pale yellow solid; IR (UATR, $\mathrm{cm}^{-1}$ ): 3536, 2975, 1600; ${ }^{1} \mathrm{H}-\mathrm{NMR}\left(300 \mathrm{MHz}, \mathrm{CDCl}_{3}\right), \delta$ (ppm): 7.53 (d, $J=8.4 \mathrm{~Hz}, 1 \mathrm{H}), 7.38(\mathrm{~d}, J=16.8 \mathrm{~Hz}, 1 \mathrm{H}), 7.32(\mathrm{~d}, J=16.5 \mathrm{~Hz}, 1 \mathrm{H}), 6.74(\mathrm{~d}, J=2.7 \mathrm{~Hz}, 1 \mathrm{H}), 6.48(\mathrm{dd}$, $J=10.8,2.4 \mathrm{~Hz}, 1 \mathrm{H}), 6.46(\mathrm{br} \mathrm{s}, 1 \mathrm{H}), 6.40(\mathrm{~d}, J=2.4 \mathrm{~Hz}, 1 \mathrm{H}), 4.49(\mathrm{~m}, 4 \mathrm{H}), 1.31-1.40(\mathrm{~m}, 24 \mathrm{H}) ;{ }^{13} \mathrm{C}-\mathrm{NMR}$ (75 MHz, $\mathrm{CDCl}_{3}$ ), $\delta$ (ppm): 158.4, 156.5, 150.7, 145.0, 138.8, 127.4, 124.6, 124.1, 121.1, 120.8, 107.5, 104.9, 103.3, 102.6, 71.8, 71.1, 71.0, 69.9, 22.2, 22.14, 22.13, 22.10; TOF-HRMS $m / z[\mathrm{M}+\mathrm{H}]^{+}$, calcd for $\mathrm{C}_{26} \mathrm{H}_{37} \mathrm{O}_{5}$ : 429.2635; found: 429.2643 .

\subsubsection{Preparation of 3-(2,4-Dihydroxyphenyl)-6,8-dihydroxyisochroman-1-one (18)}

To a solution of $15(104 \mathrm{mg}, 0.23 \mathrm{mmol})$ in dry $\mathrm{CH}_{2} \mathrm{Cl}_{2}(2 \mathrm{~mL})$, a solution of $\mathrm{BBr}_{3}(0.96 \mathrm{~mL}$, $0.96 \mathrm{mmol}$ ) in $\mathrm{CH}_{2} \mathrm{Cl}_{2}$ was added under argon at $-78^{\circ} \mathrm{C}$, and the mixture was stirred for $20 \mathrm{~min}$. After completion of the reaction, water $(5 \mathrm{~mL})$ was added, and the mixture was extracted with EtOAc $(3 \times 5 \mathrm{~mL})$. The organic phase was washed with brine, dried over $\mathrm{Na}_{2} \mathrm{SO}_{4}$, filtered and concentrated under reduced pressure to give a crude product. Purification with column chromatography eluting with $5 \% \mathrm{MeOH} / \mathrm{CH}_{2} \mathrm{Cl}_{2}$ gave $18\left(13 \mathrm{mg}, 20 \%\right.$ ). Light brown solid, $\mathrm{mp} 210-212{ }^{\circ} \mathrm{C}$; IR (UATR, $\mathrm{cm}^{-1}$ ): 3340, 3190, $1611 ;{ }^{1} \mathrm{H}-\mathrm{NMR}\left(300 \mathrm{MHz}\right.$, acetone- $\left.d_{6}\right), \delta(\mathrm{ppm}): 7.28(\mathrm{~d}, J=8.4 \mathrm{~Hz}, 1 \mathrm{H}), 6.48(\mathrm{~d}, J=2.1 \mathrm{~Hz}$, $1 \mathrm{H}), 6.43(\mathrm{dd}, J=8.4,2.4 \mathrm{~Hz}, 1 \mathrm{H}), 6.35(\mathrm{br} \mathrm{s}, 1 \mathrm{H}), 6.30(\mathrm{~d}, J=2.1 \mathrm{~Hz}, 1 \mathrm{H}), 5.83(\mathrm{dd}, J=12,3 \mathrm{~Hz}, 1 \mathrm{H})$, $3.29(\mathrm{dd}, J=16.5,12.3 \mathrm{~Hz}, 1 \mathrm{H}), 3.04(\mathrm{dd}, J=16.5,3.3 \mathrm{~Hz}, 1 \mathrm{H}) ;{ }^{13} \mathrm{C}-\mathrm{NMR}\left(75 \mathrm{MHz}\right.$, acetone- $\left.d_{6}\right), \delta$ (ppm): 171.1, 165.13, 165.07, 159.5, 156.3, 143.8, 128.9, 117.2, 107.9, 107.3, 103.4, 101.95, 101.88, 76.5, 34.4; TOF-HRMS $m / z$ [M + Na] ${ }^{+}$, calcd for $\mathrm{C}_{15} \mathrm{H}_{12} \mathrm{NaO}_{6}$ : 311.0526; found: 311.0529.

\subsubsection{Preparation of $2^{\prime}$-(E)-Carbethoxyethenyl-2, $3^{\prime}, 4,5^{\prime}$-tetraisopropoxystilbene (19)}

A solution of 14 in dry $\mathrm{CH}_{2} \mathrm{Cl}_{2}(4 \mathrm{~mL})$ was added to $\mathrm{EtO}_{2} \mathrm{CCH}=\mathrm{PPh}_{3}(176 \mathrm{mg}, 0.51 \mathrm{mmol})$ at $0{ }^{\circ} \mathrm{C}$ under argon. Then the reaction mixture was allowed to warm to room temperature and stirred overnight. After completion of the reaction, water $(5 \mathrm{~mL})$ was added, and the mixture was extracted with EtOAc $(3 \times 5 \mathrm{~mL})$. The organic layer was washed with brine, dried over $\mathrm{Na}_{2} \mathrm{SO}_{4}$, 
filtered and concentrated under reduced pressure to give a crude product. Purification with column chromatography eluting with $50 \% \mathrm{CH}_{2} \mathrm{Cl}_{2}$ /hexanes gave 19 (134 mg, 68\%). Pale yellow oil; IR (UATR, $\mathrm{cm}^{-1}$ ): 2977, 2932, 1706, 1589; ${ }^{1} \mathrm{H}-\mathrm{NMR}\left(300 \mathrm{MHz}, \mathrm{CDCl}_{3}\right), \delta(\mathrm{ppm}): 8.03(\mathrm{~d}, J=16.2 \mathrm{~Hz}, 1 \mathrm{H}), 7.45$ $(\mathrm{d}, J=8.4 \mathrm{~Hz}, 1 \mathrm{H}), 7.37(\mathrm{~d}, J=16.2 \mathrm{~Hz}, 1 \mathrm{H}), 7.15(\mathrm{~d}, J=16.2 \mathrm{~Hz}, 1 \mathrm{H}), 6.70(\mathrm{~d}, J=2.1 \mathrm{~Hz}, 1 \mathrm{H}), 6.50(\mathrm{~d}$, $J=16.2 \mathrm{~Hz}, 1 \mathrm{H}), 6.49(\mathrm{dd}, J=8.4,2.4 \mathrm{~Hz}, 1 \mathrm{H}), 6.48(\mathrm{br} \mathrm{s}, 1 \mathrm{H}), 6.39(\mathrm{~d}, J=2.1 \mathrm{~Hz}, 1 \mathrm{H}), 4.58(\mathrm{~m}, 4 \mathrm{H}), 4.24$ $(\mathrm{q}, J=7.1 \mathrm{~Hz}, 2 \mathrm{H}), 1.28-1.40(\mathrm{~m}, 27 \mathrm{H}) ;{ }^{13} \mathrm{C}-\mathrm{NMR}\left(75 \mathrm{MHz}, \mathrm{CDCl}_{3}\right), \delta(\mathrm{ppm}): 168.2,159.4,158.7,156.7$, 142.3, 139.0, 128.4, 127.4, 125.6, 120.3, 120.1, 115.8, 107.2, 105.6, 102.8, 100.8, 71.0, 70.7, 69.9, 69.8, 59.9, 22.09, 22.04, 22.00, 14.3; TOF-HRMS $m / z[\mathrm{M}+\mathrm{H}]^{+}$, calcd for $\mathrm{C}_{31} \mathrm{H}_{43} \mathrm{O}_{6}$ : 511.3054; found: 511.3077.

\subsubsection{Preparation of $3^{\prime}, 5^{\prime}$-Diacetoxy-2,4-diisopropoxystilbene (20)}

$\mathrm{Et}_{3} \mathrm{~N}(0.05 \mathrm{~mL}, 0.33 \mathrm{mmol})$ and acetic anhydride $(0.03 \mathrm{~mL}, 0.33 \mathrm{mmol})$ were added to a solution of $5(50 \mathrm{mg}, 0.15 \mathrm{mmol})$ in $\mathrm{CH}_{2} \mathrm{Cl}_{2}(2 \mathrm{~mL})$ at room temperature. The reaction mixture was stirred for $2 \mathrm{~h}$. Water $(5 \mathrm{~mL})$ was added, and the reaction mixture was extracted with EtOAc $(3 \times 5 \mathrm{~mL})$. The organic phase was washed with brine, dried over $\mathrm{Na}_{2} \mathrm{SO}_{4}$, filtered and concentrated under reduced pressure to give a crude product. Purification with column chromatography eluting with $20 \%$ EtOAc/hexanes gave 20 (46 mg, 74\%). White solid, mp 65-67 ${ }^{\circ} \mathrm{C}$; IR (UATR, $\left.\mathrm{cm}^{-1}\right)$ : 2978, 1768, 1599; ${ }^{1} \mathrm{H}-\mathrm{NMR}$ $\left(300 \mathrm{MHz}, \mathrm{CDCl}_{3}\right), \delta(\mathrm{ppm}): 7.41(\mathrm{~d}, J=8.4 \mathrm{~Hz}, 1 \mathrm{H}), 7.34(\mathrm{~d}, J=16.5 \mathrm{~Hz}, 1 \mathrm{H}), 7.08(\mathrm{~d}, J=2.1 \mathrm{~Hz}, 2 \mathrm{H})$, $6.94(\mathrm{~d}, J=16.2 \mathrm{~Hz}, 1 \mathrm{H}), 6.78(\mathrm{t}, J=2.1 \mathrm{~Hz}, 1 \mathrm{H}), 6.46(\mathrm{dd}, J=8.1,2.4 \mathrm{~Hz}, 1 \mathrm{H}), 6.45(\mathrm{br} \mathrm{s}, 1 \mathrm{H}), 4.51(\mathrm{~m}$, 2H), $2.25(\mathrm{~s}, 6 \mathrm{H}), 1.36(\mathrm{~d}, J=6 \mathrm{~Hz}, 6 \mathrm{H}), 1.31(\mathrm{~d}, J=6 \mathrm{~Hz}, 6 \mathrm{H}) ;{ }^{13} \mathrm{C}-\mathrm{NMR}\left(75 \mathrm{MHz}, \mathrm{CDCl}_{3}\right), \delta(\mathrm{ppm})$ : 168.7, 158.8, 156.6, 151.0, 140.7, 127.6, 125.8, 124.6, 119.4, 116.3, 113.3, 106.9, 102.5, 70.6, 69.7, 21.9, 21.8, 20.8; TOF-HRMS $m / z$ [M + Na] ${ }^{+}$, calcd for $\mathrm{C}_{24} \mathrm{H}_{28} \mathrm{NaO}_{6}$ : 435.1778; found: 435.1796 .

\subsubsection{Preparation of $3^{\prime}, 5^{\prime}$-Diacetoxy-5-formyl-2,4-diisopropoxystilbene (21)}

$\mathrm{POCl}_{3}(0.16 \mathrm{~mL}, 1.77 \mathrm{mmol})$ was stirred with dry DMF $(1 \mathrm{~mL})$ at room temperature for $2 \mathrm{~h}$ under argon. The solution of $20(73 \mathrm{mg}, 0.18 \mathrm{mmol})$ in dry DMF $(1 \mathrm{~mL})$ was added at $0{ }^{\circ} \mathrm{C}$. Then the reaction mixture was allowed to warm to room temperature and stirred overnight. After completion of the reaction, cool water $(5 \mathrm{~mL})$ was added, and the reaction mixture was extracted with EtOAc $(3 \times 5 \mathrm{~mL})$. The organic layer was washed with water $(7 \times 5 \mathrm{~mL})$ and brine, dried over $\mathrm{Na}_{2} \mathrm{SO}_{4}$, filtered and concentrated under reduced pressure to give a crude product, which was purified by preparative TLC (20\% EtOAc/hexanes) to furnish 21 (46 mg, 60\%). Viscous yellow oil; IR (UATR, $\mathrm{cm}^{-1}$ ): 2979, 1768, 1671, 1593; ${ }^{1} \mathrm{H}-\mathrm{NMR}\left(300 \mathrm{MHz}, \mathrm{CDCl}_{3}\right), \delta(\mathrm{ppm}): 10.32(\mathrm{~s}, 1 \mathrm{H}), 8.03(\mathrm{~s}, 1 \mathrm{H}), 7.27(\mathrm{~d}, J=16.5 \mathrm{~Hz}, 1 \mathrm{H})$, $7.08(\mathrm{~d}, J=1.8 \mathrm{~Hz}, 2 \mathrm{H}), 7.03(\mathrm{~d}, J=16.5 \mathrm{~Hz}, 1 \mathrm{H}), 6.81(\mathrm{t}, J=2.1 \mathrm{~Hz}, 1 \mathrm{H}), 6.44(\mathrm{~s}, 1 \mathrm{H}), 4.66(\mathrm{~m}, 2 \mathrm{H}), 2.29$ $(\mathrm{s}, 6 \mathrm{H}), 1.43(\mathrm{~d}, J=6 \mathrm{~Hz}, 6 \mathrm{H}), 1.40(\mathrm{~d}, J=6 \mathrm{~Hz}, 6 \mathrm{H}) ;{ }^{13} \mathrm{C}-\mathrm{NMR}\left(75 \mathrm{MHz}, \mathrm{CDCl}_{3}\right), \delta(\mathrm{ppm}): 188.1,168.7$, 161.8, 161.4, 151.0, 140.1, 126.6, 126.3, 124.2, 119.6, 118.8, 116.4, 113.8, 98.1, 71.2, 70.9, 21.67, 21.66, 20.8; TOF-HRMS $m / z$ [M $+\mathrm{Na}]^{+}$, calcd for $\mathrm{C}_{25} \mathrm{H}_{28} \mathrm{NaO}_{7}$ : 463.1727; found: 463.1743 .

\subsubsection{Preparation of 3',5'-Diacetoxy-5-carboxy-2,4-diisopropoxystilbene (22)}

A solution of $\mathrm{NaClO}_{2}(85 \mathrm{mg}, 0.93 \mathrm{mmol})$ and $\mathrm{NaH}_{2} \mathrm{PO}_{4} \cdot 2 \mathrm{H}_{2} \mathrm{O}(145 \mathrm{mg}, 0.93 \mathrm{mmol})$ in water $(0.5 \mathrm{~mL})$ was added to a solution of $21(51 \mathrm{mg}, 0.12 \mathrm{mmol})$ and 2-methyl-2-butene $(0.04 \mathrm{~mL}, 0.49 \mathrm{mmol})$ in acetone $(0.5 \mathrm{~mL})$ at room temperature. The reaction mixture was stirred for $1 \mathrm{~h}$. After completion, water $(5 \mathrm{~mL})$ was added, and the reaction mixture was extracted with EtOAc $(3 \times 5 \mathrm{~mL})$. The organic layer was washed with brine, dried over $\mathrm{Na}_{2} \mathrm{SO}_{4}$, filtered and concentrated under reduced pressure to give a crude product, which was purified by column chromatography on silica (40\% EtOAc/hexanes) to furnish 22 (39 mg, 73\%). White solid, $\mathrm{mp} 106-108^{\circ} \mathrm{C}$; IR (UATR, $\left.\mathrm{cm}^{-1}\right)$ : 3267, 2980, 1769, 1732, 1601; ${ }^{1} \mathrm{H}-\mathrm{NMR}\left(300 \mathrm{MHz}, \mathrm{CDCl}_{3}\right), \delta(\mathrm{ppm}): 8.35(\mathrm{~s}, 1 \mathrm{H}), 7.26(\mathrm{~d}, J=16.5 \mathrm{~Hz}, 1 \mathrm{H}), 7.09(\mathrm{~d}, J=2.1 \mathrm{~Hz}, 2 \mathrm{H}), 7.08$ $(\mathrm{d}, J=16.5 \mathrm{~Hz}, 1 \mathrm{H}), 6.82(\mathrm{t}, J=2.1 \mathrm{~Hz}, 1 \mathrm{H}), 6.50(\mathrm{~s}, 1 \mathrm{H}), 4.83(\mathrm{sept}, J=6 \mathrm{~Hz}, 1 \mathrm{H}), 4.65(\mathrm{sept}, J=6 \mathrm{~Hz}$, $1 \mathrm{H}), 2.31(\mathrm{~s}, 6 \mathrm{H}), 1.51(\mathrm{~d}, J=6 \mathrm{~Hz}, 6 \mathrm{H}), 1.45(\mathrm{~d}, J=6 \mathrm{~Hz}, 6 \mathrm{H}) ;{ }^{13} \mathrm{C}-\mathrm{NMR}\left(75 \mathrm{MHz}, \mathrm{CDCl}_{3}\right), \delta(\mathrm{ppm})$ : 168.9, 165.3, 160.2, 157.2, 151.2, 140.1, 132.1, 127.5, 123.9, 121.4, 116.8, 114.2, 110.9, 99.0, 74.2, 71.4, 21.92, 21.88, 21.0; TOF-HRMS $\mathrm{m} / z$ [M + Na] ${ }^{+}$, calcd for $\mathrm{C}_{25} \mathrm{H}_{28} \mathrm{NaO}_{8}$ : 479.1676; found: 479.1695 . 
3.2.18. Preparation of 5-Formyl-2,3',4,5'-tetrahydroxystilbene (23)

A solution of $\mathrm{BCl}_{3}(0.42 \mathrm{~mL}, 0.42 \mathrm{mmol})$ was added to a solution of $21(30 \mathrm{mg}, 0.07 \mathrm{mmol})$ in $\mathrm{CH}_{2} \mathrm{Cl}_{2}(2 \mathrm{~mL})$ at $-78{ }^{\circ} \mathrm{C}$ under argon. Then it was allowed to warm to room temperature and stirred overnight. Water $(5 \mathrm{~mL})$ was then added, and the reaction mixture was extracted with EtOAc $(3 \times 5 \mathrm{~mL})$. The EtOAc was washed with brine, dried over $\mathrm{Na}_{2} \mathrm{SO}_{4}$, filtered and concentrated under reduced pressure to give a crude product which was purified by preparative TLC (40\% EtOAc/hexanes) to give 23 (15 mg, 78\%). Yellow solid, decomposed $>205{ }^{\circ} \mathrm{C}$; IR (UATR, $\left.\mathrm{cm}^{-1}\right): 3208,1626 ;{ }^{1} \mathrm{H}-\mathrm{NMR}$ (300 MHz, methanol- $\left.d_{4}\right), \delta(\mathrm{ppm}): 9.69(\mathrm{~s}, 1 \mathrm{H}), 7.76(\mathrm{~s}, 1 \mathrm{H}), 7.27(\mathrm{~d}, J=16.5 \mathrm{~Hz}, 1 \mathrm{H}), 6.95(\mathrm{~d}, J=16.5 \mathrm{~Hz}$, $1 \mathrm{H}), 6.47(\mathrm{~d}, J=2.4 \mathrm{~Hz}, 2 \mathrm{H}), 6.25(\mathrm{~s}, 1 \mathrm{H}), 6.16(\mathrm{t}, J=2.1 \mathrm{~Hz}, 1 \mathrm{H}) ;{ }^{13} \mathrm{C}-\mathrm{NMR}\left(75 \mathrm{MHz}\right.$, methanol- $\left.d_{4}\right), \delta$ (ppm): 194.9, 167.8, 164.8, 159.6, 141.6, 133.2, 128.4, 123.8, 121.0, 115.5, 105.9, 103.7, 102.7; TOF-HRMS $m / z[\mathrm{M}-\mathrm{H}]^{-}$, calcd for $\mathrm{C}_{15} \mathrm{H}_{11} \mathrm{O}_{5}: 271.0612$; found: 271.0603 .

\subsubsection{Preparation of 5-Carboxy-2, $3^{\prime}, 4,5^{\prime}$-tetrahydroxystilbene (24)}

A solution of $\mathrm{BCl}_{3}(0.88 \mathrm{~mL}, 0.88 \mathrm{mmol})$ was added to a solution of $22(68 \mathrm{mg}, 0.15 \mathrm{mmol})$ in $\mathrm{CH}_{2} \mathrm{Cl}_{2}(2 \mathrm{~mL})$ at $-78{ }^{\circ} \mathrm{C}$ under argon. Then the reaction was allowed to warm to room temperature and stirred overnight. Water $(5 \mathrm{~mL})$ was added, and the mixture was extracted with EtOAc $(3 \times 5 \mathrm{~mL})$. The organic layer was washed with brine, dried over $\mathrm{Na}_{2} \mathrm{SO}_{4}$, filtered and concentrated under reduced pressure to give a crude product which was purified by Sephadex LH20 (methanol) to give $24(27 \mathrm{mg}, 63 \%)$. Yellow solid, decomposed $>230{ }^{\circ} \mathrm{C}$; IR (UATR, $\left.\mathrm{cm}^{-1}\right)$ : 3337, 1616; ${ }^{1} \mathrm{H}-\mathrm{NMR}$ (300 MHz, methanol- $\left.d_{4}\right), \delta(\mathrm{ppm}): 8.01(\mathrm{~s}, 1 \mathrm{H}), 7.24(\mathrm{~d}, J=16.5 \mathrm{~Hz}, 1 \mathrm{H}), 6.92(\mathrm{~d}, J=16.5 \mathrm{~Hz}, 1 \mathrm{H}), 6.49(\mathrm{~d}$, $J=2.1 \mathrm{~Hz}, 2 \mathrm{H}), 6.36(\mathrm{~s}, 1 \mathrm{H}), 6.19(\mathrm{t}, J=2.1 \mathrm{~Hz}, 1 \mathrm{H}) ;{ }^{13} \mathrm{C}-\mathrm{NMR}\left(75 \mathrm{MHz}\right.$, methanol- $\left.d_{4}\right), \delta(\mathrm{ppm}): 173.5$, $164.2,162.8,159.6,141.6,130.0,128.5,123.8,118.9,106.3,105.8,103.3,102.7$; TOF-HRMS $m / z$ [M - H] ${ }^{-}$, calcd for $\mathrm{C}_{15} \mathrm{H}_{11} \mathrm{O}_{6}$ : 287.0561; found: 287.0549 .

\subsubsection{Preparation of 5-Formyl-3', $5^{\prime}$-dihydroxy-2,4-diisopropoxystilbene (25)}

To 21 (59 mg, $0.12 \mathrm{mmol}), \mathrm{KOH}(5 \%$ in $\mathrm{EtOH}, 1 \mathrm{~mL})$ was added at room temperature, and the reaction mixture was stirred for $10 \mathrm{~min}$. After completion of the reaction, the reaction was extracted with EtOAc $(3 \times 5 \mathrm{~mL})$. The EtOAc phase was washed with brine, dried over $\mathrm{Na}_{2} \mathrm{SO}_{4}$, filtered and concentrated under reduced pressure to give a crude product. Purification with column chromatography eluting with 50\% EtOAc in hexanes gave 25 (41 mg, 93\%). Yellow solid, mp 186-188 ${ }^{\circ} \mathrm{C}$; IR (UATR, $\left.\mathrm{cm}^{-1}\right)$ : 3355, 2979, 1588; ${ }^{1} \mathrm{H}-\mathrm{NMR}\left(300 \mathrm{MHz}\right.$, acetone- $\left.d_{6}\right), \delta(\mathrm{ppm}): 10.32(\mathrm{~s}, 1 \mathrm{H}), 7.99(\mathrm{~s}, 1 \mathrm{H})$, $7.30(\mathrm{~d}, J=16.5 \mathrm{~Hz}, 1 \mathrm{H}), 7.05(\mathrm{~d}, J=16.5 \mathrm{~Hz}, 1 \mathrm{H}), 6.80(\mathrm{~s}, 1 \mathrm{H}), 6.59(\mathrm{~d}, J=2 \mathrm{~Hz}, 2 \mathrm{H}), 6.29(\mathrm{t}, J=2 \mathrm{~Hz}$, $1 \mathrm{H}), 4.91(\mathrm{~m}, 2 \mathrm{H}), 1.43(\mathrm{~d}, J=6.3 \mathrm{~Hz}, 6 \mathrm{H}), 1.41(\mathrm{~d}, J=6.4 \mathrm{~Hz}, 6 \mathrm{H}) ;{ }^{13} \mathrm{C}-\mathrm{NMR}\left(75 \mathrm{MHz}\right.$, acetone- $\left.d_{6}\right), \delta$ (ppm): 188.0, 162.7, 162.3, 159.6, 140.9, 129.2, 126.6, 122.9, 121.1, 120.1, 105.8, 102.9, 100.0, 72.1, 71.8, 22.2, 22.1; TOF-HRMS $m / z$ [M + H] $]^{+}$, calcd for $\mathrm{C}_{21} \mathrm{H}_{25} \mathrm{O}_{5}: 357.1696$; found: 357.1712.

\subsubsection{Preparation of 5-Carboxy-3',5'-dihydroxy-2,4-diisopropoxystilbene (26)}

To 22 (30 mg, $0.07 \mathrm{mmol}), \mathrm{KOH}(5 \%$ in $\mathrm{EtOH}, 1 \mathrm{~mL})$ was added at room temperature, and the reaction mixture was stirred for $10 \mathrm{~min}$. The reaction was acidified with $2 \mathrm{~N} \mathrm{HCl}$ to $\mathrm{pH} 5$. The material was extracted with EtOAc $(3 \times 5 \mathrm{~mL})$, and the combined organic layers were dried over $\mathrm{Na}_{2} \mathrm{SO}_{4}$, filtered, and concentrated under reduced pressure to provide $\mathbf{2 6}(10 \mathrm{mg}, 40 \%)$. Light brown solid, $\mathrm{mp}$ 112-114 ${ }^{\circ} \mathrm{C} ;{ }^{1} \mathrm{H}-\mathrm{NMR}\left(300 \mathrm{MHz}\right.$, acetone- $\left.d_{6}\right), \delta(\mathrm{ppm}): 8.23(\mathrm{~s}, 1 \mathrm{H}), 7.31(\mathrm{~d}, J=16 \mathrm{~Hz}, 1 \mathrm{H}), 7.07(\mathrm{~d}$, $J=16 \mathrm{~Hz}, 1 \mathrm{H}), 6.88(\mathrm{~s}, 1 \mathrm{H}), 6.59(\mathrm{~d}, J=2 \mathrm{~Hz}, 2 \mathrm{H}), 6.30(\mathrm{t}, J=2 \mathrm{~Hz}, 1 \mathrm{H}), 5.04(\mathrm{sept}, J=6 \mathrm{~Hz}, 1 \mathrm{H}), 4.89$ (sept, $J=6 \mathrm{~Hz}, 1 \mathrm{H}), 1.46(\mathrm{~d}, J=6.3 \mathrm{~Hz}, 6 \mathrm{H}), 1.43(\mathrm{~d}, J=6 \mathrm{~Hz}, 6 \mathrm{H}) ;{ }^{13} \mathrm{C}-\mathrm{NMR}\left(75 \mathrm{MHz}\right.$, acetone- $\left.d_{6}\right), \delta$ (ppm): 165.7, 160.8, 159.6, 158.5, 140.8, 131.5, 129.6, 122.9, 122.0, 112.7, 108.0, 103.0, 101.1, 74.4, 71.9, 22.2, 22.1; TOF-HRMS $m / z$ [M - H] $]^{-}$, calcd for $\mathrm{C}_{21} \mathrm{H}_{23} \mathrm{O}_{6}$ : 357.1500; found: 371.1502. 
3.2.22. Preparation of $3^{\prime}, 5^{\prime}$-Diacetoxy-5-hydroxy-2,4-diisopropoxystilbene (27)

A solution of $30 \%$ hydrogen peroxide $(0.03 \mathrm{~mL}, 0.192 \mathrm{mmol})$ was added to a methanolic mixture of $21(44 \mathrm{mg}, 0.10 \mathrm{mmol})$ and $p-\mathrm{TsOH} \cdot \mathrm{H}_{2} \mathrm{O}(5 \mathrm{mg}, 0.03 \mathrm{mmol})$ at $0{ }^{\circ} \mathrm{C}$. The reaction mixture was allowed to warm to room temperature and stirred for $1 \mathrm{~h}$. Half-saturated sodium sulfite solution $(1 \mathrm{~mL})$ was added, and the mixture was extracted with $\mathrm{CH}_{2} \mathrm{Cl}_{2}(3 \times 5 \mathrm{~mL})$. The $\mathrm{CH}_{2} \mathrm{Cl}_{2}$ layer was washed with brine, dried over $\mathrm{Na}_{2} \mathrm{SO}_{4}$, filtered and concentrated under reduced pressure to give a crude product. Purification with preparative TLC (30\% EtOAc/hexanes) gave 27 (19 mg, 47\%). Pale yellow solid, mp 138-140 ${ }^{\circ} \mathrm{C}$; IR (UATR, cm ${ }^{-1}$ ): 3525, 2977, 1767; ${ }^{1} \mathrm{H}-\mathrm{NMR}\left(300 \mathrm{MHz}, \mathrm{CDCl}_{3}\right), \delta(\mathrm{ppm}): 7.34$ (d, $J=16.2 \mathrm{~Hz}, 1 \mathrm{H}), 7.13(\mathrm{~s}, 1 \mathrm{H}), 7.07(\mathrm{~d}, J=2.1 \mathrm{~Hz}, 2 \mathrm{H}), 6.87(\mathrm{~d}, J=16.2 \mathrm{~Hz}, 1 \mathrm{H}), 6.79(\mathrm{t}, J=1.8 \mathrm{~Hz}, 1 \mathrm{H})$, $6.50(\mathrm{~s}, 1 \mathrm{H}), 4.54(\mathrm{sept}, J=6 \mathrm{~Hz}, 1 \mathrm{H}), 4.33(\mathrm{sept}, J=6 \mathrm{~Hz}, 1 \mathrm{H}), 2.30(\mathrm{~s}, 6 \mathrm{H}), 1.36(\mathrm{~d}, J=6.3 \mathrm{~Hz}, 6 \mathrm{H}), 1.34$ $(\mathrm{d}, J=6.3 \mathrm{~Hz}, 6 \mathrm{H}) ;{ }^{13} \mathrm{C}-\mathrm{NMR}\left(75 \mathrm{MHz}, \mathrm{CDCl}_{3}\right), \delta$ (ppm): 169.0, 151.1, 149.4, 145.0, 141.4, 140.6, 125.3, $125.2,120.9,116.5,113.7,111.3,103.7,73.3,71.8,22.2,22.0,21.0$; TOF-HRMS $\mathrm{m} / z$ [M + Na] ${ }^{+}$, calcd for $\mathrm{C}_{24} \mathrm{H}_{28} \mathrm{NaO}_{7}$ : 451.1727; found: 451.1723 .

\subsection{Biological Activities}

In this study, statistical analysis of the biological data was performed using the Student's $t$-test. All results were expressed as arithmetic mean \pm standard deviation (SD).

\subsubsection{DPPH Radical Assay}

The experiment was performed according to an established method [33]. The experiment was performed in a 96-well plate. The reduction of the DPPH was measured by reading the absorbance at $510 \mathrm{~nm}$ with a Perkin Elmer Victor ${ }^{3}$ multilabel counter. Oxyresveratrol and Trolox were used as positive controls.

\subsubsection{Superoxide Radical Assay}

The assay was based on the capacity of the sample to inhibit the reduction of nitroblue tetrazolium (NBT) in the riboflavin-light-NBT system $[18,34]$. Oxyresveratrol and Trolox were used as positive controls.

\subsubsection{Inhibitory Effect on Supercoiled DNA Breakage}

The assay was performed as previously described [18]. This assay measured the ability of the test sample to protect DNA against damage induced by the photochemical reaction of riboflavin, with oxyresveratrol and Trolox used as positive controls.

\subsubsection{Determination of Anti-Herpes Simplex Virus Activity}

Anti-HSV activities of the compounds were determined using a modified plaque reduction assay, with acyclovir as a positive control [35].

\subsubsection{Neuraminidase (NA) Inhibition Assay}

This assay was performed using the method previously described by Potier and co-workers [36]. The fluorescence was measured using SpectraMax M5 multi-detection microplate reader (Molecular Devices, Sunnyvale, CA, USA) with excitation and emission wave lengths of 365 and $450 \mathrm{~nm}$, respectively. Oseltamivir was used as a positive control.

\subsubsection{Determination of $\alpha$-Glucosidase Inhibitory Activity}

The assay was performed in a 96-well plate and based on the capacity of the sample to inhibit the hydrolysis of $p$-nitrophenyl- $\alpha$-D-glucoside (PNPG) by $\alpha$-glucosidase to release $p$-nitrophenol (PNP), a yellow color agent that can be monitored at $405 \mathrm{~nm}$ [20]. Acarbose was used as a positive control. 


\subsubsection{Determination of Cytotoxic Activity}

The assays for cytotoxicity were carried out according to a previous report [37]. Cell viability was determined using MTT assay. Doxorubicin was used as the positive control.

\section{Conclusions}

A total of 26 derivatives were prepared from oxyresveratrol (1) through several types of reactions. Selective di-O-alkylation is possible because the two hydroxy groups at C-2 and C-4 of ring A of $\mathbf{1}$ are obviously more reactive than those on ring $\mathrm{B}$. Electrophilic substitution on the $\mathrm{B}$ ring is more facile than on the A ring. However, the relative reactivity can be reversed by manipulating the type and the number of protecting groups. Through this strategy, electrophilic substitution reactions can be selectively directed to ring A or B. This finding has provided a new and useful approach for the future chemical modification of similarly oxygenated aromatic structures.

Compound 1 and analogs 2-27 were evaluated for a number of biological activities, including free radical scavenging activity, DNA protective properties, antiherpetic activity, inhibition of $\alpha$-glucosidase and neuraminidase, and cytotoxicity against some cancer cell lines. Some of the derivatives were equally active or more potent than the parent compound. It is interesting to note that the partially etherified products $3^{\prime}, 5^{\prime}$-dihydroxy-2,4-dimethoxystilbene (2) and 5'-hydroxy-2,3', 4-trimethoxystilbene (3) demonstrated encouraging antiherpetic and DNA protective activities. Compared with the parent compound, 2 and 3 should have higher lipophilicity, and thus should have greater potential as preventive agents for neurodegenerative diseases. $5^{\prime}$-Hydroxy-2, $3^{\prime}, 4$,-triisopropoxystilbene (6), an etherified analog with retained anti- $\alpha$-glucosidase activity but with a potentially slower rate of metabolism than that of $\mathbf{1}$, should be a better lead for oral anti-diabetic drug development. In addition, the mixed esterified/etherified derivative 3',5'-diacetoxy-2,4-diisopropoxystilbene (20) displayed pronounced in vitro cytotoxicity against HeLa cells, and warrants further investigation in animals.

Acknowledgments: We are grateful to the Thailand Research Fund for a research grant (BRG 5580004). Thanks are also due to the Research Instrument Center of the Faculty of Pharmaceutical Sciences, Chulalongkorn University for providing research facilities. For cytotoxicity assays, Pakamas Intachote (Laboratory of Immunology, Chulabhorn Research Institute) and Suchada Sengsai (Integrated Research Unit, Chulabhorn Research Institute) are greatly appreciated.

Author Contributions: Nutputsorn Chatsumpun, Poonsakdi Ploypradith and Kittisak Likhitwitayawuid conceived and designed the research, and prepared the manuscript. Nutputsorn Chatsumpun, Taksina Chuanasa, Boonchoo Sritularak, Vimolmas Lipipun and Vichien Jongbunprasert performed the experiments. Somsak Ruchirawat contributed chemical reagents and analysis tools. Poonsakdi Ploypradith and Kittisak Likhitwitayawuid co-supervised the project.

Conflicts of Interest: The authors declare no conflict of interest.

\section{References}

1. Riviere, C.; Pawlus, A.D.; Merillon, J.M. Natural stilbenoids: Distribution in the plant kingdom and chemotaxonomic interest in Vitaceae. Nat. Prod. Rep. 2012, 29, 1317-1333. [CrossRef] [PubMed]

2. Gorham, J. The Biochemistry of the Stilbenoids; Chapman \& Hall: London, UK, 1995; pp. 56-166.

3. Niesen, D.B.; Hessler, C.; Seeram, N.P. Beyond resveratrol: A review of natural stilbenoids identified from 2009-2013. J. Berry Res. 2013, 3, 181-196.

4. Rainsford, K.D. Influenza ("Bird Flu”), inflammation and anti-inflammatory/analgesic drugs. Inflammopharmacology 2006, 14, 2-9. [CrossRef] [PubMed]

5. Pereira, A.C.; Arruda, M.S.P.; Da Silva, E.A.S.; Da Silva, M.N.; Lemos, V.S.; Cortes, S.F. Inhibition of $\alpha$-glucosidase and hypoglycemic effect of stilbenes from the Amazonian plant Deguelia rufescens var urucu (Ducke) A.M.G. Azevedo (Leguminosae). Planta Med. 2012, 78, 36-38. [CrossRef] [PubMed]

6. Su, P.S.; Doerksen, R.J.; Chen, S.H.; Sung, W.C.; Juan, C.C.; Rawendra, R.D.S.; Chen, C.R.; Li, J.W.; Aisha; Huang, T.C.; et al. Screening and profiling stilbene-type natural products with angiotensin-converting enzyme inhibitory activity from Ampelopsis brevipedunculata var. hancei (Planch.) Rehder. J. Pharm. Biomed. 2015, 108, 70-77. [CrossRef] [PubMed] 
7. Lin, T.K.; Chen, S.D.; Chuang, Y.C.; Lin, H.Y.; Huang, C.R.; Chuang, J.H.; Wang, P.W.; Huang, S.T.; Tiao, M.M.; Chen, J.B.; et al. Resveratrol partially prevents rotenone-induced neurotoxicity in dopaminergic SH-SY5Y cells through induction of heme oxygenase-1 dependent autophagy. Int. J. Mol. Sci. 2014, 15, 1625-1646. [CrossRef] [PubMed]

8. Maneechai, S.; Likhitwitayawuid, K.; Sritularak, B.; Palanuvej, C.; Ruangrungsi, N.; Sirisa-ard, P. Quantitative analysis of oxyresveratrol content in Artocarpus lakoocha and "Puag-Haad". Med. Princ. Pract. 2009, 18, 223-227. [CrossRef] [PubMed]

9. Likhitwitayawuid, K.; Sornsute, A.; Sritularak, B.; Ploypradith, P. Chemical transformations of oxyresveratrol (trans-2,4,3',5'-tetrahydroxystilbene) into a potent tyrosinase inhibitor and a strong cytotoxic agent. Bioorg. Med. Chem. Lett. 2006, 16, 5650-5653. [CrossRef] [PubMed]

10. Tengamnuay, P.; Pengrungruangwong, K.; Pheansri, I.; Likhitwitayawuid, K. Artocarpus lakoocha heartwood extract as a novel cosmetic ingredient: Evaluation of the in vitro anti-tyrosinase and in vivo skin whitening activities. Int. J. Cosmetic Sci. 2006, 28, 269-276. [CrossRef] [PubMed]

11. Likhitwitayawuid, K.; Sritularak, B.; Benchanak, K.; Lipipun, V.; Mathew, J.; Schinazi, R.F. Phenolics with antiviral activity from Millettia erythrocalyx and Artocarpus lakoocha. Nat. Prod. Res. 2005, 19, 177-182. [CrossRef] [PubMed]

12. Lipipun, V.; Sasivimolphan, P.; Yoshida, Y.; Daikoku, T.; Sritularak, B.; Ritthidej, G.; Likhitwitayawuid, K.; Pramyothin, P.; Hattori, M.; Shiraki, K. Topical cream-based oxyresveratrol in the treatment of cutaneous HSV-1 infection in mice. Antivir. Res. 2011, 91, 154-160. [CrossRef] [PubMed]

13. Civitelli, L.; Marcocci, M.E.; Celestino, I.; Piacentini, R.; Garaci, E.; Grassi, C.; De Chiara, G.; Palamara, A.T. Herpes simplex virus type 1 infection in neurons leads to production and nuclear localization of APP intracellular domain (AICD): Implications for Alzheimer's disease pathogenesis. J. Neurovirol. 2015, 21, 480-490. [CrossRef] [PubMed]

14. Ban, J.Y.; Jeon, S.Y.; Nguyen, T.T.H.; Bae, K.; Song, K.S.; Seong, Y.H. Neuroprotective effect of oxyresveratrol from Smilacis chinae rhizome on amyloid $\beta$ protein (25-35)-induced neurotoxicity in cultured rat cortical neurons. Biol. Pharm. Bull. 2006, 29, 2419-2424. [CrossRef] [PubMed]

15. Jeon, S.Y.; Kwon, S.H.; Seong, Y.H.; Bae, K.; Hur, J.M.; Lee, Y.Y.; Suh, D.Y.; Song, K.S. Beta-secretase (BACE1)-inhibiting stilbenoids from Smilax Rhizoma. Phytomedicine 2007, 14, 403-408. [CrossRef] [PubMed]

16. Chao, J.; Yu, M.S.; Ho, Y.S.; Wang, M.; Chang, R.C.C. Dietary oxyresveratrol prevents parkinsonian mimetic 6-hydroxydopamine neurotoxicity. Free Radic. Biol. Med. 2008, 45, 1019-1026. [CrossRef] [PubMed]

17. Andrabi, S.A.; Spina, M.G.; Lorenz, P.; Ebmeyer, U.; Wolf, G.; Horn, T.F.W. Oxyresveratrol (trans-2,3',4,5'-tetrahydroxystilbene) is neuroprotective and inhibits the apoptotic cell death in transient cerebral ischemia. Brain Res. 2004, 1017, 98-107. [CrossRef] [PubMed]

18. Chatsumpun, M.; Chuanasa, T.; Sritularak, B.; Likhitwitayawuid, K. Oxyresveratrol protects against DNA damage induced by photosensitized riboflavin. Nat. Prod. Commun. 2011, 6, 41-44. [PubMed]

19. Kongkamnerd, J. Development of Non-Cell Based Assays for Screening of Inhibitiors against Avian Influenza Neuraminidase. Ph.D. Thesis, Chulalongkorn University, Bangkok, Thailand, 2010.

20. He, H.; Lu, Y.-H. Comparison of inhibitory activities and mechanisms of five mulberry plant bioactive components against $\alpha$-glucosidase. J. Agric. Food Chem. 2013, 61, 8110-8119. [CrossRef] [PubMed]

21. Huang, H.; Chen, G.; Lu, Z.; Zhang, J.; Guo, D.A. Identification of seven metabolites of oxyresveratrol in rat urine and bile using liquid chromatography/tandem mass spectrometry. Biomed. Chromatogr. 2010, 24, 426-432. [CrossRef] [PubMed]

22. Breuer, C.; Wolf, G.; Andrabi, S.A.; Lorenz, P.; Horn, T.F. Blood-brain barrier permeability to the neuroprotectant oxyresveratrol. Neurosci. Lett. 2006, 393, 113-118. [CrossRef] [PubMed]

23. Joshi, P.C. Comparison of the DNA-damaging property of photosensitised riboflavin via singlet oxygen $\left({ }^{1} \mathrm{O}_{2}\right)$ and superoxide radical $\left(\mathrm{O}_{2}{ }^{-}\right)$mechanisms. Toxicol. Lett. 1985, 26, 211-217. [CrossRef]

24. Lu, C.-Y.; Wang, W.-F.; Lin, W.-Z.; Han, Z.-H.; Yao, S.-D.; Lin, N.-Y. Generation and photosensitization properties of the oxidized radical of riboflavin: A laser flash photolysis study. J. Photochem. Photobiol. B Biol. 1999, 52, 111-116. [CrossRef]

25. Korycka-Dahl, M.; Richardson, T. Photogeneration of superoxide anion in serum of bovine milk and in model systems containing riboflavin and amino acids. J. Dairy Sci. 1977, 61, 400-407. [CrossRef] 
26. Cardoso, D.R.; Olsen, K.; Skibsted, L.H. Mechanism of deactivation of triplet-excited riboflavin by ascorbate, carotenoids, and tocopherols in homogeneous and heterogeneous aqueous food model systems. J. Agric. Food Chem. 2007, 55, 6285-6291. [CrossRef] [PubMed]

27. Mori, T.; Tano, K.; Takimoto, K.; Utsumi, H. Formation of 8-hydroxyguanine and 2,6-diamino-4-hydroxy-5-formamidopyrimidine in DNA by riboflavin mediated photosensitization. Biochem. Biophys. Res. Commun. 1998, 242, 98-101. [CrossRef] [PubMed]

28. Li, C.; Fang, J.S.; Lian, W.W.; Pang, X.C.; Liu, A.L.; Du, G.H. In vitro antiviral effects and 3D QSAR study of resveratrol derivatives as potent inhibitors of influenza H1N1 neuraminidase. Chem. Biol. Drug. Des. 2015, 85, 427-438. [CrossRef] [PubMed]

29. Sritularak, B.; De-Eknamkul, W.; Likhitwitayawuid, K. Tyrosinase inhibitors from Artocarpus lakoocha. Thai J. Pharm. Sci. 1988, 22, 149-155.

30. Chuanasa, T.; Phromjai, J.; Lipipun, V.; Likhitwitayawuid, K.; Suzuki, M.; Pramyothin, P.; Hattori, M.; Shiraki, K. Anti-herpes simplex virus (HSV-1) activity of oxyresveratrol derived from Thai medicinal plant: Mechanism of action and therapeutic efficacy on cutaneous HSV-1 infection in mice. Antivir. Res. 2008, 80, 62-70. [CrossRef] [PubMed]

31. Sornsute, A. Isolation and Structure Modification of Oxyresveratrol from Artocarpus lakoocha for Tyrosinase Activity. Master's Thesis, Chulalongkorn University, Bangkok, Thailand, 2006.

32. Park, J.; Park, J.H.; Suh, H.J.; Lee, I.C.; Koh, J.; Boo, Y.C. Effects of resveratrol, oxyresveratrol, and their acetylated derivatives on cellular melanogenesis. Arch. Dermatol. Res. 2014, 306, 475-487. [CrossRef] [PubMed]

33. Likhitwitayawuid, K.; Klongsiriwet, C.; Jongbunprasert, V.; Sritularak, B.; Wongseripipatana, S. Flavones with free radical scavenging activity from Goniothalamus tenuifolius. Arch. Pharm. Res. 2006, 29, 199-202. [CrossRef] [PubMed]

34. Dasgupta, N.; De, B. Antioxidant activity of Piper betle L. leaf extract in vitro. Food Chem. 2004, 88, $219-224$. [CrossRef]

35. Lipipun, V.; Kurokawa, M.; Suttisri, R.; Taweechotipatr, P.; Pramyothin, P.; Hattori, M.; Shiraki, K. Efficacy of Thai medicinal plant extracts against herpes simplex virus type 1 infection in vitro and in vivo. Antivir. Res. 2003, 60, 175-180. [CrossRef]

36. Potier, M.; Mameli, L.; Bélisle, M.; Dallaire, L.; Melançon, S.B. Fluorometric assay of neuraminidase with a sodium (4-methylumbelliferyl- $\alpha$-D-N-acetylneuraminate) substrate. Anal. Biochem. 1979, 94, 287-296. [CrossRef]

37. Tangdenpaisal, K.; Worayuthakarn, R.; Karnkla, S.; Ploypradith, P.; Intachote, P.; Sengsai, S.; Saimanee, B.; Ruchirawat, S.; Chittchang, M. Designing new analogs for streamlining the structure of cytotoxic lamellarin natural products. Chem. Asian J. 2015, 10, 925-937. [CrossRef] [PubMed]

Sample Availability: Samples of the compounds are available from the authors.

(c) 2016 by the authors; licensee MDPI, Basel, Switzerland. This article is an open access article distributed under the terms and conditions of the Creative Commons Attribution (CC-BY) license (http:/ / creativecommons.org/licenses/by/4.0/). 